\title{
Simulation of anthropogenic $\mathrm{CO}_{2}$ uptake in the CCSM3.1 ocean circulation-biogeochemical model: comparison with data-based estimates
}

\author{
S. Wang ${ }^{1}$, J. K. Moore ${ }^{1}$, F. W. Primeau ${ }^{1}$, and S. Khatiwala ${ }^{2}$ \\ ${ }^{1}$ Earth System Science, University of California, Irvine, Irvine, CA 92697, USA \\ ${ }^{2}$ Lamont Doherty Earth Observatory, Columbia University, Palisades, NY 10964, USA
}

Correspondence to: S. Wang (shanlinw@ucar.edu)

Received: 6 October 2011 - Published in Biogeosciences Discuss.: 9 November 2011

Revised: 13 March 2012 - Accepted: 16 March 2012 - Published: 11 April 2012

\begin{abstract}
The global ocean has taken up a large fraction of the $\mathrm{CO}_{2}$ released by human activities since the industrial revolution. Quantifying the oceanic anthropogenic carbon $\left(\mathrm{C}_{\text {ant }}\right)$ inventory and its variability is important for predicting the future global carbon cycle. The detailed comparison of data-based and model-based estimates is essential for the validation and continued improvement of our prediction capabilities. So far, three global estimates of oceanic $\mathrm{C}_{\mathrm{ant}}$ inventory that are "data-based" and independent of global ocean circulation models have been produced: one based on the $\Delta \mathrm{C}^{*}$ method, and two that are based on constraining surface-to-interior transport of tracers, the TTD method and a maximum entropy inversion method (GF). The GF method, in particular, is capable of reconstructing the history of $\mathrm{C}_{\mathrm{ant}}$ inventory through the industrial era. In the present study we use forward model simulations of the Community Climate System Model (CCSM3.1) to estimate the $\mathrm{C}_{\mathrm{ant}}$ inventory and compare the results with the data-based estimates. We also use the simulations to test several assumptions of the GF method, including the assumption of constant climate and circulation, which is common to all the data-based estimates. Though the integrated estimates of global $\mathrm{C}_{\mathrm{ant}}$ inventories are consistent with each other, the regional estimates show discrepancies up to $50 \%$. The CCSM 3 model underestimates the total $\mathrm{C}_{\text {ant }}$ inventory, in part due to weak mixing and ventilation in the North Atlantic and Southern Ocean. Analyses of different simulation results suggest that key assumptions about ocean circulation and air-sea disequilibrium in the GF method are generally valid on the global scale, but may introduce errors in $\mathrm{C}_{\mathrm{ant}}$ estimates on regional scales. The GF method should also be used with caution when predicting future oceanic anthropogenic carbon uptake.
\end{abstract}

\section{Introduction}

Since the industrial revolution, a large amount of carbon dioxide $\left(\mathrm{CO}_{2}\right)$ has been emitted into the atmosphere due to human activities. Increased atmospheric $\mathrm{CO}_{2}$ is the largest contributor to the anthropogenic Greenhouse effect (Solomon et al., 2007). Given the importance of $\mathrm{CO}_{2}$ to climate, it is crucial to understand the global carbon cycle. The ocean plays an important role in the global carbon cycle, modulating atmospheric $\mathrm{CO}_{2}$ concentrations and climate. The global ocean has taken up 20 to 35 percent of $\mathrm{CO}_{2}$ released by human activities since the industrial revolution (Khatiwala et al., 2009; Sabine et al., 2004; Houghton, 2007). Some studies have suggested that the oceanic carbon sink may have changed during the past few decades (Wang and Moore, 2012; Lovenduski et al., 2007; Le Quéré et al., 2007; Wetzel et al., 2005; Perez et al., 2010b), though significant uncertainties remain (e.g. McKinley et al., 2011). Quantifying the oceanic carbon inventory and its variability is therefore important for understanding the global carbon cycle and how it might change over time.

Anthropogenic carbon concentrations in the ocean cannot be measured directly and the magnitude of the anthropogenic carbon signal is only a few percent of the large natural background. Substantial effort has been made to estimate the oceanic anthropogenic $\mathrm{CO}_{2}$ inventory and variability based on observational data and model simulations in recent years (Hall et al., 2004; Khatiwala et al., 2009; Álvarez et al., 2009; Mikaloff Fletcher et al., 2006; Sabine et al., 2004; Waugh et al., 2006). Generally, assessments of the oceanic $\mathrm{CO}_{2}$ uptake based on observations can be made in two ways. One strategy is to estimate the uptake rates by repeated hydrographic measurements of the carbon 
system over time (e.g. Brown et al., 2010; Peng et al., 1998, 2003; Peng and Wanninkhof, 2010; Perez et al., 2010a; Murata et al., 2008, 2009; Sabine et al., 2008; Tanhua et al., 2007). However, interpreting the changes is complicated by the fact that the ocean carbon system exhibits significant natural variability on different timescales, from seasonal to decadal and longer timescales, and on different spatial scales. The variability complicates the investigation of oceanic anthropogenic carbon uptake rates and causes uncertainties in estimates of ocean carbon inventory. As suggested by Wanninkhof et al. (2010), large biogeochemical changes could introduce biases in the extended Multiple Linear Regression (eMLR) method, which is a widely used method based on repeated hydrographic measurements. Goodkin et al. (2011) found that secular climate changes and changes in carbonate chemistry invalidate the use of the eMLR technique over time periods beyond $2-4$ decades and result in significant errors in the eMLR based estimates of oceanic anthropogenic $\mathrm{CO}_{2}$ uptake.

The second strategy is to use back-calculation methods (e.g. Gruber et al., 1996; Goyet et al, 1999; Tanhua et al., 2007; Touratier and Goyet, 2004; Touratier et al., 2007) and tracer-based calculations (e.g. Hall et al., 2002; Waugh et al., 2006; Khatiwala et al., 2009) to estimate the anthropogenic carbon uptake. Since the estimates by Brewer (1978) and Chen and Millero (1979), several alternative back-calculation methods have been developed to estimate anthropogenic $\mathrm{CO}_{2}$ concentrations in the ocean. Of these, one of the most widely used is the $\Delta C^{*}$ method developed by Gruber et al. (1996). The $\Delta C^{*}$ method starts with measured dissolved inorganic carbon (DIC) data. Biological and natural $\mathrm{CO}_{2}$ solubility components of the DIC are removed with measured oxygen, nutrients, alkalinity and other observational data. The residual is interpreted as the anthropogenic signal. The first global estimate of $\mathrm{C}_{\text {ant }}$ inventory was carried out by applying this method to a subset of the Global Ocean Data Analysis Project (GLODAP) dataset (Sabine et al., 2004). The $\Delta C^{*}$ method is predicated on several assumptions. First, the air-sea disequilibrium is constant. Second, the biological pump is constant and known. It also assumes constant ocean circulation with weak mixing. A previous study by Matsumoto and Gruber (2005) has evaluated uncertainties of the $\Delta C^{*}$ method with a global ocean biogeochemical model. Their results suggested that major biases arose from the assumption of constant disequilibrium and a single ventilation age.

A second approach is based on exploiting tracer observations (Hall et al., 2002). This method exploits the smallness of the anthropogenic perturbation to treat anthropogenic carbon as a passive, inert tracer. As a consequence, its concentration in the interior can be related to its time evolving history in the surface mixed layer via a Green function, the distribution of times needed for water to be transported from the surface to the interior (or transit time distribution (TTD)). This approach, known as the TTD method, assumes that biological productivity does not alter the uptake of anthropogenic carbon and that biological processes are not involved in the transport of tracers. The TTD method relaxes the assumption of a single ventilation time and avoids the need for uncertain biological corrections in the $\Delta \mathrm{C}^{*}$ method. The along-isopycnal mixing of water masses of different ages is explicitly taken into account. Observational data are used to estimate the transit time distribution (i.e. the Green function) (Hall et al., 2002). The TTD method has been applied to assessments of oceanic anthropogenic carbon inventory (Hall et al., 2004; Waugh et al., 2004, 2006). Previous studies suggested that the assumptions of a single surface source region for water and anthropogenic $\mathrm{CO}_{2}$, constant disequilibrium, the selection of a particular functional form for the Green function and the measurement limitation of transient tracers are probably the largest sources of error in the TTD estimates (Hall et al., 2004; Waugh et al., 2006).

Recently, Khatiwala et al. (2009) developed another method, which is known as the Green Function (GF) method. This approach is also based on the notion of a TTD, but extends and improves it in several aspects. The TTD method utilizes a type of Green function, whose form is parameterized by two variables, a mean and width. In the TTD approach, CFC observations are used to constrain the mean (assuming that the mean equals the width). In the GF approach, no functional form is assumed for the Green function. Instead, a maximum entropy inverse technique is used to constrain the ocean's Green function with multiple steady and transient tracers. The GF method also relaxes a number of (potentially incorrect) assumptions made in the $\Delta C^{*}$ method and/or the TTD method. Specifically, in the GF method, airsea disequilibrium is allowed to evolve in space and time, and the mixing of waters of both different ages and different end-member types is taken into account. Khatiwala et al. (2009) applied this method to the GLODAP database to provide the first data-based estimate of the time-evolving, three-dimensional anthropogenic carbon distribution in the ocean starting at the beginning of the industrial revolution, unlike previous estimates which provided only a snapshot of the $\mathrm{C}_{\mathrm{ant}}$ distribution. Another advantage of the GF method is that it can, in principal, be used to predict future anthropogenic carbon inventories in the ocean, given a projection of the future atmospheric $\mathrm{CO}_{2}$ concentrations. The validity of such an estimate would however depend on the not only the projected atmospheric $\mathrm{CO}_{2}$ concentration, but also changes in the ocean's circulation and biological pump remaining small.

Previous observations suggest ongoing changes in the ocean. The heat content of the world ocean has increased substantially over the past few decades (Levitus et al., 2000, 2005) along with the global averaged sea surface temperature (Hansen et al., 2006, 2010). Dissolved oxygen concentrations have also decreased in several ocean basins (Stramma et al., 2009; Matear et al., 2000; Andreev and Watanabe, 2002; Keller et al., 2002). These changes can affect the air-sea 
$\mathrm{CO}_{2}$ flux and the carbon pumps, and therefore impact carbon storage in the ocean. For example, warmer sea-surface temperature causes increases in the partial pressure of $\mathrm{CO}_{2}$ in the surface ocean. Elevated temperature can also increase seawater buffer capacity. These two effects of temperature affect ocean carbon uptake, yet oppose each other. Temperature changes also have significant impact on the growth rate of phytoplankton, which are key players in transporting carbon to the deep ocean. Changing oxygen concentrations and circulation can affect nutrient cycling and distributions, which influence the efficiency of the biological pump. Moreover, some previous research has found that enriched $\mathrm{CO}_{2}$ could affect ocean biological productivity (Palacios and Zimmerman, 2007; Riebesell et al., 2007). It is also likely that ocean circulation will change in the future as the climate continues to change. With a reduced meridional overturning circulation and convective mixing, the transport of $\mathrm{CO}_{2}$ into the ocean interior may slow down and oceanic carbon uptake decreases. Currently, all the data-based estimates of anthropogenic carbon uptake assume constant climate and ocean circulation. Also, the biological pump is assumed to be constant and known (the $\Delta C^{*}$ method) (Gruber et al., 1996) or unimportant in the sequestration of anthropogenic carbon (the TTD and GF methods) (Waugh et al., 2006; Khatiwala et al., 2009). These assumptions may introduce significant errors in studies of future anthropogenic carbon uptake.

Coupled carbon cycle-ocean circulation models have also been used to estimate the ocean anthropogenic $\mathrm{CO}_{2}$ inventory and assist the understanding of the global carbon cycle (e.g. Orr et al., 2001; Xu and Li, 2009). The strength of global carbon cycle models embedded within climate models is that they can take into account the impact of changes in future climate. Such models can also provide us with the opportunity to evaluate and interpret data-based estimates. However, given limited resolution and other model imperfections, carbon-cycle models do not necessarily agree with constraints provided by hydrographic tracer observations for the current era. It is necessary to evaluate the performance of carbon cycle models against data-based estimates of the anthropogenic carbon uptake. Several models have been evaluated in this way (Álvarez et al., 2009; Xu and Li, 2009; Orr et al., 2001). Discrepancies exist among different databased estimates and uncertainties are caused by various assumptions. In a recent review, Sabine and Tanhua (2010) summarized advantages and disadvantages of several different data-based methods, including the TTD method and the $\Delta C^{*}$ method, but without a full assessment of each method. Some earlier data-based methods have been evaluated using carbon cycle model simulated data (Matsumoto and Gruber, 2005; Yool et al., 2010; Levine et al., 2008).

Different estimates of oceanic anthropogenic carbon uptake have different strengths and weakness. The first step of improvement in estimates is detailed comparisons of different widely-used methods and understanding biases and uncertainties in these methods. One objective of this study is to compare anthropogenic carbon inventory estimated using the GF method and previous global estimates from the $\Delta \mathrm{C}^{*}$ method and the TTD method. Another objective is to evaluate the ability of a coupled carbon cycle-ocean circulation model to estimate oceanic anthropogenic carbon uptake and compare it with different data-based estimates of anthropogenic carbon inventory in detail. Lastly, we use model simulations to assess assumptions made in the GF method that have not previously been evaluated.

\section{Methods and model description}

\subsection{Coupled carbon cycle - ocean circulation model}

The ocean circulation model used in this study is the coarse resolution, ocean circulation component of the National Center for Atmospheric Research (NCAR) Community Climate System Model 3.1 (CCSM3.1) (Collins et al., 2006; Yeager et al., 2006). The carbon cycle was simulated with an ocean biogeochemical/ecosystem model, the Biogeochemical Elemental Cycling (BEC) model (Moore et al., 2002, 2004). The model includes 25 vertical levels with 8 levels in the upper $103 \mathrm{~m}$. It has $100 \times 116$ horizontal grid points. The longitudinal resolution is $3.6^{\circ}$ and the latitudinal resolution varies in the range of $0.9^{\circ}-2.0^{\circ}$, with finer resolution near the equator. The wind speed-mixing relation in the model was adjusted to better match the observed mixed layer depths in the Southern Ocean (de Boyer Montégut et al., 2004). This modification significantly reduces the model's mixed layer depth bias, from $18 \mathrm{~m}$ too shallow in the standard CCSM 3.1 model to a bias of $2 \mathrm{~m}$ too deep in the Southern Ocean (Wang and Moore, 2011).

The BEC model includes five phytoplankton functional groups, one zooplankton group and the biogeochemical cycling of multiple growth limiting nutrients (nitrate, ammonium, phosphate, iron and silicate) (Wang and Moore, 2011; Moore et al., 2004). The five phytoplankton groups are diatoms, diazotrophs, small phytoplankton, coccolithophores and Phaeocystis (Wang and Moore, 2011). The light, nutrient-, and temperature-dependencies of phytoplankton growth rate are modeled multiplicatively. Phytoplankton growth rates decrease under nutrient stress according to Michaelis-Menten nutrient uptake kinetics. Phytoplankton photoadaptation is described by varying chlorophyll to nitrogen ratios based on the model of Geider et al. (1998). Ecosystem parameters were chosen based on field and laboratory data and were described in detail by Moore et al. (2004, 2002) and Wang and Moore (2011). The ecosystem module is coupled with an ocean biogeochemistry module, which includes full carbonate system thermodynamics and air-sea $\mathrm{CO}_{2}$ and $\mathrm{O}_{2}$ fluxes. The atmosphere component is not coupled in this study. Atmospheric conditions, including atmospheric $\mathrm{CO}_{2}$ concentrations, are prescribed boundary conditions, so that there is no oceanic feedback to the atmosphere. 
The model was spun up for 600 years with repeating $\mathrm{Na}-$ tional Center for Environmental Prediction/National Center for Atmospheric Research (NCEP/NCAR) meteorological reanalysis climatology data and satellite-based estimates of climatological sea ice cover (Large and Yeager, 2004) to allow tracer fields in the model to approach an approximate steady state. The initial distributions of nutrients, inorganic carbon and alkalinity were based on the World Ocean Atlas (WOA) 2001 database (Conkright et al., 2002) and the GLODAP database (Key et al., 2004). Dissolved iron initialization was based on simulations from Moore and Braucher (2008). Dust deposition was the repeating annual climatology by Luo et al. (2003). Atmospheric $\mathrm{CO}_{2}$ concentration was set to be $278 \mathrm{ppm}$ for the model initialization. Model year 600 corresponded to year 1764 .

Four simulations (summarized in Table 1) were conducted following the initial spin-up of 600 years. The control simulation (Ctrl) was a continuation of the spin-up run, forced with the same repeating climatology data. Atmospheric $\mathrm{CO}_{2}$ concentration remained fixed at $278 \mathrm{ppm}$. The control run represents the pre-industrial scenario. The second simulation (Cexp) was also forced with repeating climatology data, but the atmospheric $\mathrm{CO}_{2}$ concentrations was prescribed according to the reconstructed historical record starting in 1765. In the third and fourth simulations, labeled Fexp and Texp, the coupled model was forced with a repeating climatological surface forcing until year 1947, at which point the NCEP/NCAR 6-hourly data for momentum, heat, and freshwater fluxes (Large and Yeager, 2009) were then used instead of the climatological boundary forcing. The Ice fraction satellite data were from the Scanning Multichannel Microwave Radiometer (SMMR) from 1978 to 1988 and Special Sensor Microwave/Imager after 1988 (Large and Yeager, 2004). For the period prior to 1978 where satellite ice fraction data were unavailable, we used climatological sea ice data. In Fexp, the atmospheric $\mathrm{CO}_{2}$ concentration was kept fixed at $278 \mathrm{ppm}$, while in Texp we used the reconstructed atmospheric $\mathrm{CO}_{2}$ concentrations for the years from 1765 onwards. Both Fexp and Texp represent scenarios where changing climate is taken into account. Model performance was previously evaluated against biogeochemical and physical observations (Wang and Moore, 2011, 2012).

\subsection{Definitions of anthropogenic carbon $\left(\mathrm{C}_{\mathrm{ant}}\right)$}

There are several different definitions for the anthropogenic carbon. In data-based methods, the ocean circulation over the industrial period is generally assumed to be constant (although the GF method allows for a seasonal cycle). Furthermore, while the GF method allows a time-varying air-sea disequilibrium of $\mathrm{CO}_{2}$, both the $\Delta \mathrm{C}^{*}$ and TTD methods assume it to be constant. Given these assumptions, oceanic anthropogenic carbon should be defined as the uptake of $\mathrm{CO}_{2}$ emitted by human activitity, given the premise of approximately constant natural carbon system and constant climate. It is equivalent to the difference between DIC concentrations in the Cexp simulation and in the $\mathrm{Ctrl}$ simulation, i.e. $\mathrm{C}_{\mathrm{ant}}$ cnst $=[\mathrm{DIC}]_{\mathrm{Cexp}}-[\mathrm{DIC}]_{\mathrm{Ctr}}$.

Oceanic carbon uptake can be affected by climate, ocean circulation, and chemical properties of seawater. Changing temperatures can influence both the uptake capacity for $\mathrm{C}_{\mathrm{ant}}$ and the potential strength of the solubility pump (as reviewed by Friis, 2006). Changes in sea-surface temperature can also influence the distribution of phytoplankton and the efficiency of the biological pump. Elevated $\mathrm{CO}_{2}$ level is altering the seawater carbon chemistry and causing ocean acidification, which also influence sea-surface $p \mathrm{CO}_{2}$ and ocean carbon uptake. Compared with $\mathrm{C}_{\text {ant_cnst }}$, a better definition of oceanic anthropogenic carbon should include the effects of $\mathrm{CO}_{2}$ induced climate change on $\mathrm{C}_{\mathrm{ant}}$ uptake. This effect is neglected in data-based methods, but can be estimated in coupled circulation-carbon cycle models. To calculate the anthropogenic carbon inventory based on this definition, the formula should be $\mathrm{C}_{\text {ant_var }}=[\mathrm{DIC}]_{\text {Texp }}-[\mathrm{DIC}]_{\text {Fexp }}$.

As suggested by Keeling (2005), the definition of the $C_{a n t}$ used in data-based methods may be an incomplete measure of the change in the ocean carbon content, since the natural carbon system may also change under anthropogenic perturbations. There is another definition, which is transferred from the definition of atmospheric anthropogenic $\mathrm{CO}_{2}$. The anthropogenic portion of $\mathrm{CO}_{2}$ in the atmosphere is commonly known as the $\mathrm{CO}_{2}$ concentration difference between modern time and pre-industrial era, i.e. the increased part of $\mathrm{CO}_{2}$. This definition represents both gross $\mathrm{CO}_{2}$ emissions by human activities and effects on atmospheric $\mathrm{CO}_{2}$ due to changes in uptakes of $\mathrm{CO}_{2}$ by land and ocean as a result of changing climate. A similar definition for the oceanic anthropogenic carbon is usually used in modeling studies (Sarmiento et al., 1992; Le Quéré et al., 2010; Tjiputra et al., 2010), which represents the oceanic uptake of increased atmospheric $\mathrm{CO}_{2}$ and changes in the biological pump and the natural DIC storage due to changing climate. The formula used to calculate the complete $\mathrm{C}_{\text {ant }}$ is $\mathrm{C}_{\text {ant_all }}=[\mathrm{DIC}]_{\mathrm{Texp}}-$ $[\mathrm{DIC}]_{\mathrm{Ctrl}}$. To evaluate the complete feedback between the ocean carbon system and climate, it is necessary to consider both changes in the natural carbon cycle and emitted anthropogenic $\mathrm{CO}_{2}$.

\subsection{Reviewing the assumptions made in the Green function (GF) method}

The GF method is a generalization of the TTD method. Like the latter, it makes several assumptions. First, the anthropogenic carbon perturbation is assumed to be a conservative tracer and its distribution in the ocean is only related to physical processes, i.e. the GF method neglects possible changes in the biological pump. The GF estimate of $C_{\text {ant }}$ uptake makes use of a Green function, $\mathrm{G}$, which is obtained by deconvolving steady and transient tracer data under a constant climate assumption. The Green function is then used 
Table 1. Simulation descriptions and definition of $\mathrm{C}_{\mathrm{ant}}$

\begin{tabular}{|c|c|c|c|}
\hline \multicolumn{4}{|c|}{ Simulation Descriptions } \\
\hline Simulation & $\mathrm{AtmCO}_{2}$ & Forcing & Description \\
\hline Ctrl & $278 \mathrm{ppm}$ & constant climate & $\begin{array}{l}\text { provides information of oceanic DIC distributions } \\
\text { under the pre-industrial scenario }\end{array}$ \\
\hline Cexp & ramp up after 1765 & constant climate & $\begin{array}{l}\text { provides information of anthropogenic carbon } \\
\text { storage in the ocean under constant climate }\end{array}$ \\
\hline Fexp & $278 \mathrm{ppm}$ & varying climate after 1948 & $\begin{array}{l}\text { provides information of changes in natural } \\
\text { oceanic carbon system under the changing climate }\end{array}$ \\
\hline Texp & ramp up after 1765 & varying climate after 1948 & $\begin{array}{l}\text { represents the combined effects of rising atmospheric } \mathrm{CO}_{2} \\
\text { and the changing climate on oceanic carbon storage }\end{array}$ \\
\hline \multicolumn{4}{|c|}{ Definitions of $\mathrm{C}_{\mathrm{ant}}$} \\
\hline Definition & & & Description \\
\hline $\begin{array}{l}\mathrm{C}_{\text {ant_cnst }} \\
\mathrm{C}_{\text {ant_var }} \\
\mathrm{C}_{\text {ant_all }}\end{array}$ & & & $\begin{array}{l}{[\mathrm{DIC}]_{\mathrm{Cexp}}-[\mathrm{DIC}]_{\mathrm{Ctrl}}} \\
{[\mathrm{DIC}]_{\operatorname{Texp}}-[\mathrm{DIC}]_{\mathrm{Fexp}}} \\
{[\mathrm{DIC}]_{\operatorname{Texp}}-[\mathrm{DIC}]_{\mathrm{Ctrl}}}\end{array}$ \\
\hline
\end{tabular}

to propagate the surface history of the anthropogenic carbon, $\mathrm{C}_{\mathrm{ant}}^{\mathrm{s}}$, into the ocean interior.

In order to estimate the (unknown) surface history $C_{\text {ant }}^{\mathrm{s}}$ of anthropogenic carbon, the GF method makes use of mass conservation, namely, the rate of change of inventory of $\mathrm{C}_{\mathrm{ant}}$ is equal to the instantaneous air-sea flux of $\mathrm{C}_{\mathrm{ant}}$. The rate of change of inventory is given in terms of the convolution of the Green function with $\mathrm{C}_{\mathrm{ant}}^{\mathrm{s}}$, while the flux is proportional to the change in surface disequilibrium of $\mathrm{CO}_{2}$. The GF method assumes that this change in air-sea disequilibrium $\left(\delta \Delta p \mathrm{CO}_{2}\right)$ at any given point is proportional to the anthropogenic $\mathrm{CO}_{2}$ perturbation in the atmosphere, $\left(\delta p \mathrm{CO}_{2}^{\mathrm{atm}}\right)$,

$\delta \Delta p \mathrm{CO}_{2} \approx \varepsilon^{*} \delta p \mathrm{CO}_{2}^{\mathrm{atm}}$,

where the proportionality constant, $\varepsilon$, is a function of space. This assumption, justified on the basis of simulations in a carbon cycle model, together with the $\mathrm{CO}_{2}$ system equilibrium chemistry in seawater allows the known atmospheric $\mathrm{CO}_{2}$ history to be related to the surface $\mathrm{C}_{\text {ant }}^{\mathrm{s}}$ concentration. The unknown proportionality constant is then constrained by imposing mass conservation and requiring that the computed surface $p \mathrm{CO}_{2}$ value for the year 2000 matches the observed value in the Takahashi database (Takahashi et al., 2009) (see Khatiwala et al., (2009) for details).

\subsection{Estimates of the $\Delta C^{*}$ method and the TTD method}

Estimates of global anthropogenic carbon distributions by the $\Delta \mathrm{C}^{*}$ method $\left(\mathrm{C}_{\text {ant_}} \Delta C *\right.$ ) and the TTD method $\left(\mathrm{C}_{\text {ant_TTD }}\right)$ were obtained from the GLODAP data website (http://cdiac. ornl.gov/oceans/glodap/GlopDV.html). Both estimates were made on subsets of the GLODAP dataset (Waugh et al., 2006; Key et al., 2004; Sabine et al., 2004). The calculations using the $\Delta \mathrm{C}^{*}$ method were made in different studies (Lee et al., 2003; Sabine et al., 2002, 1999) with slight differences in the detailed techniques and synthesized by Sabine et al. (2004, 2005). There are occurrences of negative values of anthropogenic carbon concentrations, mainly due to mapping errors and uncertainties in the dataset, which were set to zero by Sabine et al. (2004). These negative values are not physically possible, and are set to zero in comparisons of column inventories (Fig. 1) and total inventories (Table 2). However, the uncorrected regional inventories are also included in Table 2 . In comparisons of regional anthropogenic carbon vertical distributions (Fig. 3), these negative values are kept to show the uncertainties in the method.

Global estimates by the TTD method were made by Waugh et al. (2006) with a pointwise version of this method applied to temperature, salinity and CFC-12 from the GLODAP dataset. The TTD method overestimated anthropogenic carbon concentrations in deep waters when CFC-12 is near or below the measurement detection limit of $\sim 0.005 \mathrm{pmol} \mathrm{kg}^{-1}$ (Waugh et al., 2006). This bias yields an anthropogenic carbon concentration of $2.5 \mu \mathrm{mol} \mathrm{kg}-1$. In calculations of regional and global inventories estimated using the TTD method, all values of anthropogenic carbon concentrations less than $2.5 \mu \mathrm{mol} \mathrm{kg} \mathrm{kg}^{-1}$ are set to zero (Waugh et al., 2006). Based on model evaluations of the TTD method, it was found that the TTD method overestimated the global anthropogenic carbon inventory by $\sim 20 \%$, with the largest biases in the Southern Ocean. Waugh et al. (2006) corrected this positive bias by reducing the global anthropogenic carbon inventory by $20 \%$. The positive bias was not corrected in data comparisons in this study, since the non-uniform pattern of the bias make the correction difficult. 
a) $C_{\text {ant- }-\Delta \mathrm{C}^{*}}$ column inventory in $1994\left(\mathrm{~mol} / \mathrm{m}^{2}\right)$

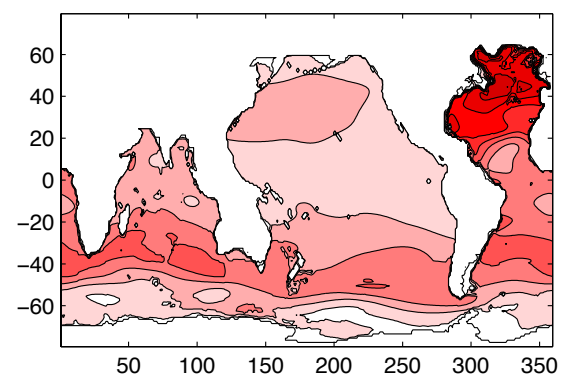

c) $C_{\text {ant-GF }}$ column inventory in $1994\left(\mathrm{~mol} / \mathrm{m}^{2}\right)$

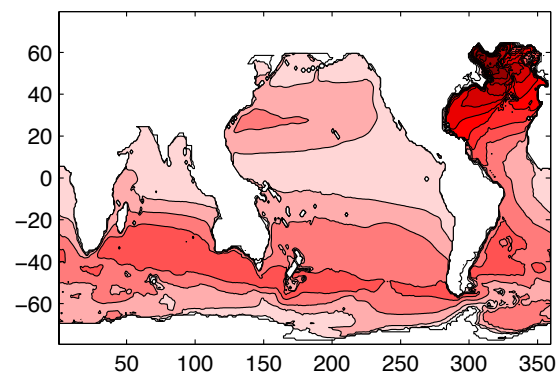

b) $C_{\text {ant-TTD }}$ column inventory in $1994\left(\mathrm{~mol} / \mathrm{m}^{2}\right)$

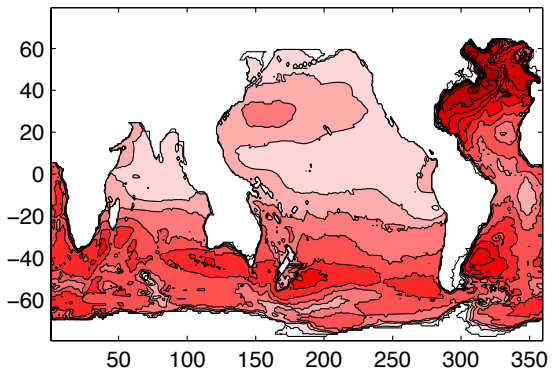

d) $\mathrm{C}_{\text {ant-cnst }}$ column inventory (CCSM) in $1994\left(\mathrm{~mol} / \mathrm{m}^{2}\right)$

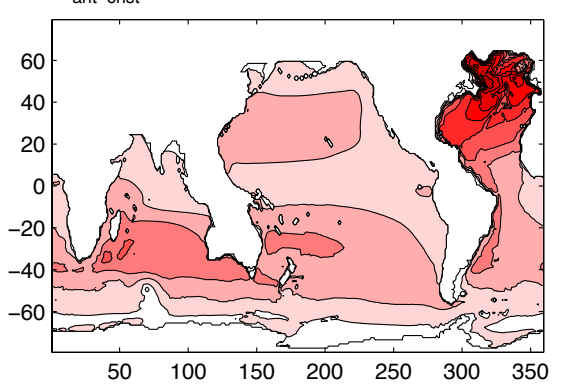

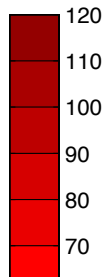

50

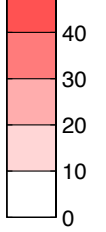

Fig. 1. Column inventories of anthropogenic DIC in year 1994 by (a) the $\Delta C^{*}$ method; (b) the TTD method; (c) the GF method; (d) the $\operatorname{CCSM}\left(\mathrm{C}_{\text {ant_cnst }}\right)$.

Table 2. Regional and global distributions of $\mathrm{C}_{\text {ant }}$ inventories in 1994 (in $\mathrm{PgC}$ )

\begin{tabular}{|c|c|c|c|c|c|c|c|}
\hline Region & $\Delta C^{*}$ method & Uncorrected $\Delta \mathrm{C}^{* 1}$ & TTD method & GF method & CCSM C $\mathrm{C}_{\text {ant_cnst }}$ & CCSM C $_{\text {ant_var }}$ & CCSM C $_{\text {ant_all }}$ \\
\hline N. Pacific & 16 & 14 & 17 & 18 & 18 & 18 & 17 \\
\hline S. Pacific & 13 & 12 & 18 & 16 & 15 & 14 & 15 \\
\hline N. Indian & 3 & 3 & 2 & 2 & 2 & 2 & 2 \\
\hline S. Indian & 11 & 9 & 11 & 11 & 10 & 10 & 10 \\
\hline N. Atlantic & 22 & 21 & 24 & 22 & 18 & 18 & 18 \\
\hline S. Atlantic & 10 & 8 & 11 & 8 & 6 & 6 & 6 \\
\hline Southern Ocean ${ }^{2}$ & 30 & 27 & 49 & 36 & 22 & 23 & 23 \\
\hline Global & 106 & 94 & $133^{3}$ & 114 & 92 & 91 & 93 \\
\hline
\end{tabular}

1 The values are obtained when negative values are kept in calculations

2 The Southern Ocean is defined as south of $35^{\circ} \mathrm{S}$.

3 The value calculated by Waugh et al. (2006) is $134 \mathrm{PgC}$. The difference may occur due to rounding error.

\section{Results and discussion}

\subsection{Oceanic anthropogenic carbon inventory}

\subsubsection{Global and regional inventories}

Since estimates based on the $\Delta C^{*}$ and TTD methods are only available for 1994, we first compare the oceanic anthropogenic carbon inventories from the data based estimates and the model simulations for that year. The global inventory estimated using the $\Delta C^{*}$ method is $106 \pm 17 \mathrm{PgC}$ (Sabine et al., 2004), while that from the TTD method was in the range of 94-121 PgC. The TTD-based inventory has been corrected for a positive bias of $\sim 20 \%$ as per model-based evaluations (Waugh et al., 2006). The uncorrected $\mathrm{C}_{\text {ant_TTD }}$ is $134 \mathrm{PgC}$, as shown in Fig. 1 and Table 2. The $\mathrm{C}_{\text {ant }} \mathrm{C} *$ is corrected by setting negative values to zero. The uncorrected $\mathrm{C}_{\text {ant }} \mathrm{C} *$ is $94 \mathrm{PgC}$ (Table 2). The inventory estimated using the GF method ( $\mathrm{C}_{\text {ant_GF }}$ ) was $114 \pm 22 \mathrm{PgC}$ (Khatiwala et al., 2009). These estimates, which are based on the GLODAP dataset, only include the open ocean, i.e. marginal seas and the Arctic Ocean are excluded. The same mask is applied to the CCSM output to make the results comparable. 
The global inventory of anthropogenic carbon simulated with CCSM is at the lower end of the data-based estimates, but falls within their uncertainty. The CCSM $\mathrm{C}_{\text {ant_cnst }}$ is $92 \mathrm{PgC}$ in the constant climate scenario (Cexp). This is about $20 \%$ lower than $\mathrm{C}_{\text {ant_GF }}$ and about $14 \%$ lower than $\mathrm{C}_{\text {ant_TTD }}$ and $\mathrm{C}_{\text {ant }} \mathrm{C} *$. Despite the nominal agreement with the previously quoted error bars, we believe that the CCSM estimate is likely low for reasons to be discussed later. The CCSM simulated $\mathrm{C}_{\mathrm{ant}}$ under varying climate is similar to that under constant climate on both global and regional scales.

The column inventories from data-based estimates and CCSM simulations show a similar pattern, with high column inventories in the North Atlantic and the Southern Ocean (Fig. 1). Regional inventories of anthropogenic carbon from different methods are compared in Table 2 . The various estimates agree best in the Indian Ocean. The total $\mathrm{C}_{\mathrm{ant}}$ in the Indian Ocean is $\sim 13 \mathrm{PgC}$, with $\sim 2 \mathrm{PgC}$ in the North Indian Ocean and $\sim 11 \mathrm{PgC}$ in the South Indian Ocean $\left(>35^{\circ} \mathrm{S}\right)$. When the area south of $35^{\circ} \mathrm{S}$ is included, the values of $\mathrm{C}_{\mathrm{ant}}$ are larger than $20 \mathrm{PgC}$, which is greater than the estimate of $\mathrm{C}_{\mathrm{ant}}$ in the Indian Ocean in the year 2000 by Hall and Primeau (2004) and Hall et al. (2004). Except the $\mathrm{C}_{a n t_{\Delta}} \mathrm{C}_{*}$, all other $\mathrm{C}_{\mathrm{ant}}$ estimates in the deep South Indian Ocean reveal penetration of anthropogenic carbon, consistent with results by Álvarez et al. (2009). Estimates of $C_{\text {ant }}$ in the Pacific Ocean are also consistent, in the range of $29 \mathrm{PgC}-35 \mathrm{PgC}$ with the lower bound set by $\mathrm{C}_{\text {ant_cnst }}$ and the upper bound set by $\mathrm{C}_{\mathrm{ant}} \mathrm{TD}$ (Table 2).

Estimated inventories of $\mathrm{C}_{\text {ant }}$ have less agreement in the Atlantic Ocean and the Southern Ocean. The $\mathrm{C}_{\text {ant_TTD }}$ in the Southern Ocean is much larger than other estimates (Fig. 2 and Table 2). Model evaluations of the TTD method suggested that the TTD method overestimated the $\mathrm{C}_{\mathrm{ant}}$ inventory by $60 \%$ in the Southern Ocean, due to a positive bias in the deep convection region primarily caused by the assumption of constant disequilibrium (Waugh et al., 2006). $C_{a n t}$ inventories estimated using the $\Delta \mathrm{C}^{*}$ and GF methods are the same in the North Atlantic Ocean, but the regional patterns of column inventories are different (Fig. 2). The column inventories of $\mathrm{C}_{\text {ant_GF }}$ are higher in deep water formation region of the North Atlantic Ocean and lower in the low to midlatitude region of the North Atlantic Ocean. These regional differences are averaged out over the entire North Atlantic Ocean. The estimated $C_{a n t} \Delta C *$ in the Southern Ocean is also significantly smaller than the $\mathrm{C}_{\text {ant_GF}}$, mainly because of the assumption of constant disequilibrium made in the $\Delta C^{*}$ method (Khatiwala et al., 2009). Previous model evaluation suggested that the $\Delta C^{*}$-based estimate showed significant deviations from the "true" value in the high-latitude North Atlantic Ocean and the Southern Ocean and indicated that the estimate from this method may be erroneous in these regions (Levine et al., 2008). The estimated $C_{a n t}$ from the CCSM is smaller than estimates using data-based methods in both the Atlantic Ocean and the Southern Ocean (Table 2 and Fig. 2). Compared with the GF method, the CCSM is
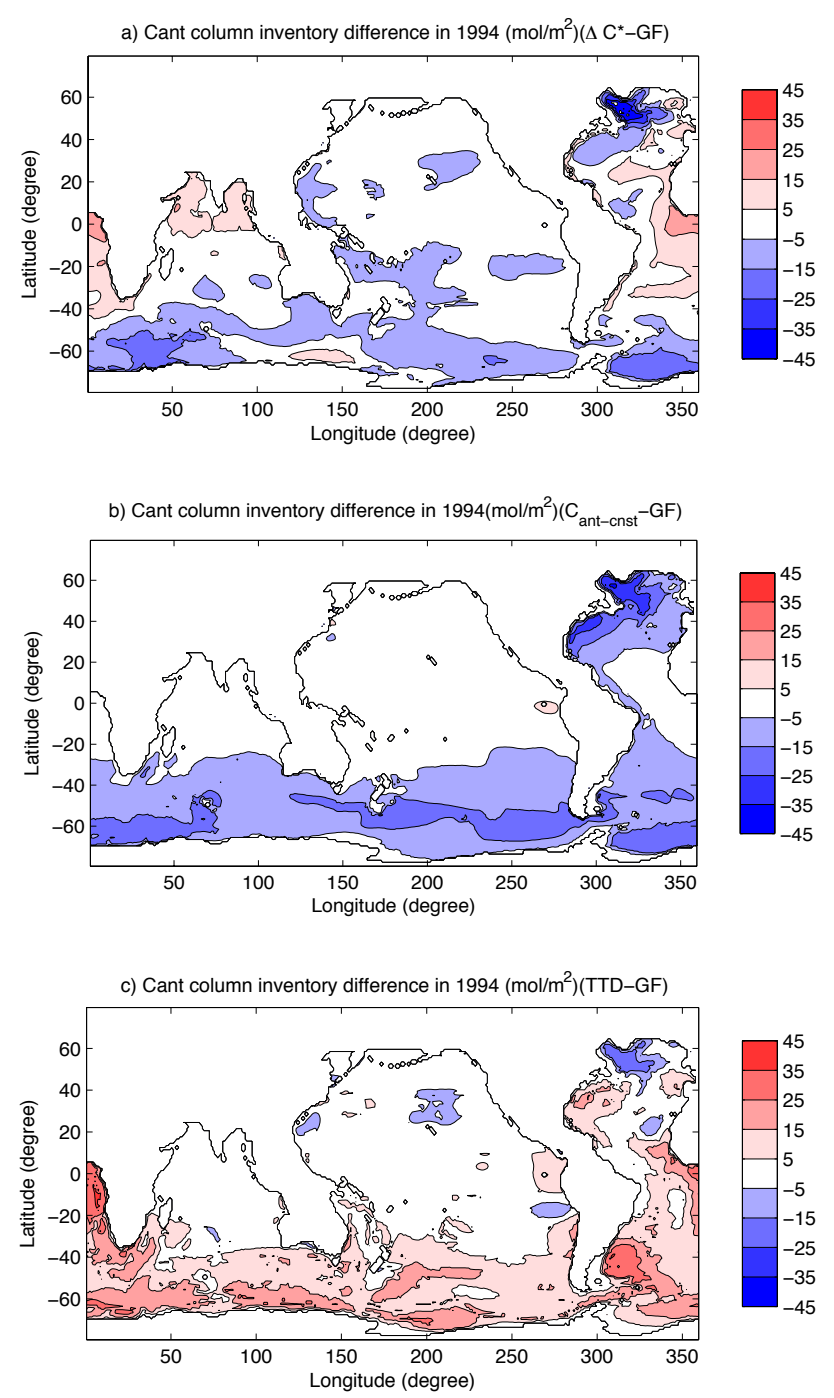

Fig. 2. Differences in column inventories between (a) the $\Delta C^{*}$ method and the GF method; (b) the CCSM ( $\left.\mathrm{C}_{\text {ant_cnst }}\right)$ and the GF method; (c) the TTD method and the GF method.

$18 \%$ and $33 \%$ lower in the North Atlantic Ocean and the Southern Ocean, respectively. It is likely that the CCSM underestimates the $\mathrm{C}_{\mathrm{ant}}$ in these two regions. The mixing in the CCSM is relatively weak at high latitudes, especially in the Southern Ocean. A previous study has suggested that the weak formation and ventilation of Antarctic Intermediate Water and mode waters in the Southern Ocean in the CCSM may cause a weak oceanic carbon sink (Thornton et al., 2009). If we include the Atlantic sector of the Southern Ocean, $\mathrm{C}_{\mathrm{ant}}$ from the $\Delta \mathrm{C}^{*}$ method, the GF method, and from the CCSM are smaller than the estimate of VázquezRodríguez et al. (2009), who suggested that the $C_{\text {ant }}$ inventory in the South Atlantic Ocean was $22 \pm 5 \mathrm{PgC}$ in 1994. Estimates for the North Atlantic Ocean cannot be compared directly with Vázquez-Rodríguez et al. (2009)'s study because 
of the different latitude ranges used in each estimate. However, the estimate for the North Atlantic Ocean using the TTD method is on the low end of all estimates in the study by Vázquez-Rodríguez et al. (2009), but nevertheless is the largest of all estimates in our comparisons.

\subsubsection{Vertical profiles of $\mathbf{C}_{\text {ant }}$}

As shown in Fig. 2 and Table 2, regional distributions of anthropogenic carbon estimated using different methods can be very different, although the total regional inventories are similar. Figure 3 shows vertical profiles of the regionallyaveraged $\mathrm{C}_{\text {ant }}$ from data-based methods and the CCSM. The Southern Ocean is defined as areas south of $35^{\circ} \mathrm{S}$. Regionally averaged $\mathrm{C}_{\text {ant }}$ vertical profiles estimated using different methods show a similar pattern. Surface $\mathrm{C}_{\text {ant }}$ concentrations are in the range of $45-57 \mathrm{mmol} \mathrm{m}^{-3}$ in most regions. The lowest surface $\mathrm{C}_{\mathrm{ant}}$ values are in the Southern Ocean, in the range of $38-41 \mathrm{mmol} \mathrm{m}^{-3}$. In most regions, $C_{\text {ant }}$ values decrease rapidly with depth down to about $1000 \mathrm{~m}$ to $1500 \mathrm{~m}$, and then remain approximately constant and low in deeper waters. The concentrations of $\mathrm{C}_{\mathrm{ant}}$ in deep waters are highest in the North Atlantic Ocean, where there is strong deep convection and mixing. The upper-ocean $\mathrm{C}_{\mathrm{ant}}$ estimates from different methods are wide-ranging in most regions, especially in the Southern Hemisphere (Fig. 3).

As mentioned above, there are some problematic values in estimates using the $\Delta C^{*}$ method and the TTD method. The $\Delta C^{*}$ method produces negative values in deep waters in all regions. This is probably due to technical errors and uncertainties of the method, but the cause is unclear (Waugh et al., 2006; Sabine et al., 2005). The negative values indicate certain issues in the $\Delta C^{*}$ method, which suggests clear problems in accuracies of the estimates of $\mathrm{C}_{\mathrm{ant}}$. Compared with the other methods, values of $\mathrm{C}_{\text {ant }}$ based on the TTD method are highest in deep waters in most regions, especially in the Atlantic Ocean and the Southern Ocean. One major source of uncertainties in the TTD is the assumption of constant disequilibrium, used for estimating the surface $\mathrm{C}_{\mathrm{ant}}$ history. A previous study showed that estimated $\mathrm{C}_{\mathrm{ant}}$ in the TTD method overestimated the $\mathrm{C}_{\text {ant }}$ inventory by $5-10 \%$ (Hall et al., 2004). Waugh et al. (2004) suggested that the estimated $\mathrm{C}_{\mathrm{ant}}$ with constant disequilibrium assumption most likely represented the upper bounds of $\mathrm{C}_{\text {ant }}$. Thus, high values of $\mathrm{C}_{\text {ant_TTD }}$ shown in Fig. 3 likely overestimate the $\mathrm{C}_{\mathrm{ant}}$ inventory.

The estimated $\mathrm{C}_{\mathrm{ant}}$ in the GF method is likely more realistic than the other two estimates. The $\mathrm{C}_{\text {ant }}$ estimated using the GF method usually falls in the middle of the range of all estimated $\mathrm{C}_{\mathrm{ant}}$ in these comparisons. The values of $\mathrm{C}_{\text {ant_TTD }}$ should be lower than the $\mathrm{C}_{\text {ant }} \mathrm{C} *$, which assumes no mixing of waters (Hall et al., 2004; Olsen et al., 2010). The global $\mathrm{C}_{\text {ant }}$ inventory from the TTD method by Waugh et al. (2006) is under the assumption of constant disequilibrium in the industrial era. The estimate should be lowered if varying disequilibrium is allowed in calculations, especially in younger waters (Waugh et al., 2004; Hall et al., 2004). The GF method, which is a generalization of the TTD method, is also based on the assumption that anthropogenic $\mathrm{CO}_{2}$ can be treated as a conservative tracer. But it relaxes some assumptions in the TTD method. The GF method includes the mixing of waters with different ages and types and allows the disequilibrium to evolve through time. The allowance for an increasing air-sea disequilibrium explains why the $\mathrm{C}_{\text {ant }}$ inventory estimated using the GF method is generally smaller than that from the TTD method. The differences in assumptions and considerations between the TTD method and the GF method also explain why the $\mathrm{C}_{\text {ant_TTD }}$ needs to be corrected for the positive bias, while the GF method does not require such a correction.

The regionally-averaged $\mathrm{C}_{\text {ant }}$ estimated using the CCSM exhibits roughly similar vertical profiles with other estimated $\mathrm{C}_{\mathrm{ant}}$, but with some differences in the details. The $\mathrm{C}_{\mathrm{ant}}$ cnst from the CCSM falls on the upper end of all estimates in the upper $200 \mathrm{~m}$ in the Indian Ocean and the Pacific Ocean. There is a good agreement between the $\mathrm{C}_{\text {ant_cnst }}$ and the $\mathrm{C}_{\text {ant_TTD }}$ in the upper $200 \mathrm{~m}$ in the Atlantic Ocean, but both are $\sim 5 \mathrm{mmol} \mathrm{m}^{-3}$ higher than the $\mathrm{C}_{\text {ant_GF}}$. The $\mathrm{C}_{\text {ant }}$ estimated using the CCSM turns out to be lower than other estimates of $\mathrm{C}_{\mathrm{ant}}$ below $400 \mathrm{~m}$. There are clear differences between the regional averaged $\mathrm{C}_{\text {ant_cnst }}$ and the $\mathrm{C}_{\text {ant_all }}$, whereas the later one includes impacts of varying climate. The differences between the $C_{\text {ant_cnst }}$ and the $C_{\text {ant_all }}$ are in the range of $-4 \mathrm{mmol} \mathrm{m}^{-3} \sim 6 \mathrm{mmol} \mathrm{m}^{-3}$ in the upper $1000 \mathrm{~m}$. The largest difference between the $\mathrm{C}_{\text {ant_cnst }}$ and other data-based $\mathrm{C}_{\mathrm{ant}}$ are located along ventilation pathways, between $1000 \mathrm{~m}$ and $2500 \mathrm{~m}$ in the North Atlantic Ocean and between $500 \mathrm{~m}$ and $1500 \mathrm{~m}$ in the Southern Ocean. These differences are mainly due to weak mixing and ventilation in the Southern Ocean and the North Atlantic Ocean in the CCSM (Thornton et al., 2009). The weak downward transport of $\mathrm{CO}_{2}$ in these two regions causes the CCSM to underestimate the global $\mathrm{C}_{\text {ant }}$ inventory. The differences between the modeled $C_{\text {ant }}$ and the $C_{\text {ant_GF }}$ during 1948 to 2003 are also shown in Fig. 4. The global $\mathrm{C}_{\mathrm{ant}}$ inventories estimated using the CCSM increase from $\sim 45 \mathrm{PgC}$ to $\sim 107 \mathrm{PgC}$ from 1948 to 2003 , while the $\mathrm{C}_{\text {ant_GF }}$ inventories increase from $57 \mathrm{PgC}$ to $132 \mathrm{PgC}$. Through the study period, the $\mathrm{C}_{\text {ant }}$ estimated using the CCSM changes proportionally to the $\mathrm{C}_{\mathrm{ant}} \mathrm{GF}$, a value

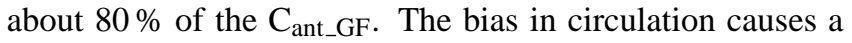
bias in the uptake of anthropogenic carbon. The accumulation of this bias leads to increasing differences between the model simulated $\mathrm{C}_{\mathrm{ant}}$ and the GF estimate.

\subsection{Assessment of assumptions of the GF method}

There are three major assumptions in the GF method as reviewed in Sect. 2.3. With these assumptions, the GF method can estimate the time-varying distribution of $\mathrm{C}_{\mathrm{ant}}$ in the ocean, given tracer observations and the atmospheric $\mathrm{CO}_{2}$ 

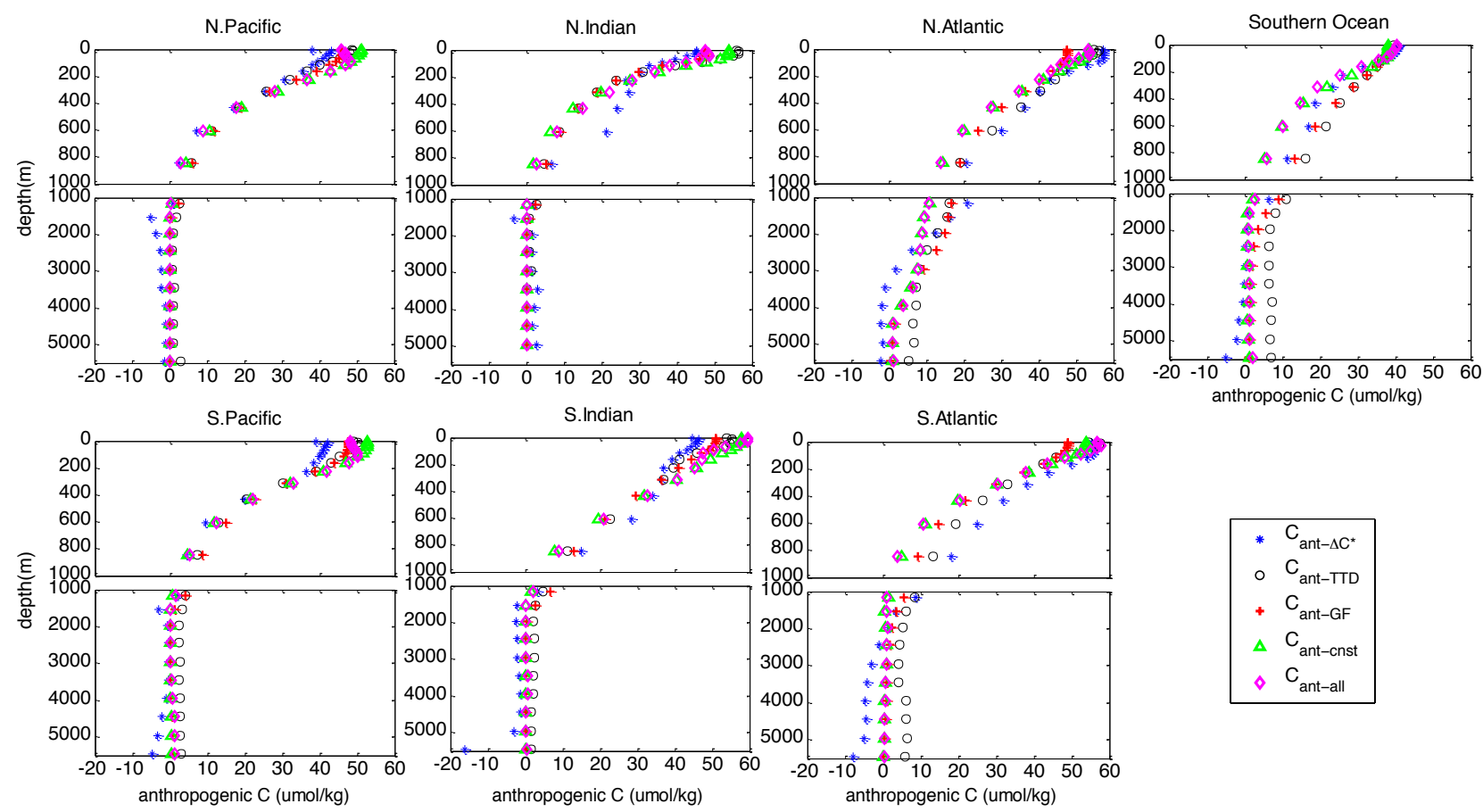

Fig. 3. Comparison of regional averaged $C_{a n t}$ from the $\Delta C^{*}$ method (blue asterisks), the TTD method (black circles), the GF method (red crosses), the $\mathrm{C}_{\text {ant_cnst }}$ from the CCSM (green triangles), and the $\mathrm{C}_{\text {ant_all }}$ from the CCSM (magenta diamonds). The Southern Ocean is south of $35^{\circ} \mathrm{S}$. Data are vertically interpolated to compare values at the same depth.

history. This provides an opportunity to understand the evolution of the oceanic $\mathrm{C}_{\mathrm{ant}}$ inventory. The estimated uncertainties of the global $\mathrm{C}_{\mathrm{ant}}$ inventory from the GF method are around $\pm 20 \%$, which includes uncertainties from tracer observations, gas-transfer coefficient, and the uncertainty in estimating the Green function from a limited number of tracer observations (Khatiwala et al., 2009). Other potential sources of error arise from the assumptions of constant circulation, constant biological production, and a linear relationship between $\delta \Delta p \mathrm{CO}_{2}$ and $\delta p \mathrm{CO}_{2}^{\text {atm }}$. These errors, which have not been previously assessed, are evaluated here.

Some earlier research found increased $\mathrm{CO}_{2}$ uptake by phytoplankton and seagrasses under higher $\mathrm{CO}_{2}$ conditions (Palacios and Zimmerman, 2007; Riebesell et al., 2007). These results suggest that enriched $\mathrm{CO}_{2}$ may stimulate ocean biological productivity and modify the cycling of nutrients, indicating possible biological effects on anthropogenic carbon uptake. Under such conditions, $\mathrm{C}_{\mathrm{ant}}$ may not behave as a conservative tracer, although the strength of these effects is poorly constrained and likely smaller than the quoted uncertainty of the GF method. It would be useful to evaluate such effects, but the BEC model does not include influences of changes in $\mathrm{CO}_{2}$ concentrations on phytoplankton growth or calcification, i.e., the biology does not change with rising $\mathrm{CO}_{2}$. The coupled BEC/CCSM is therefore not capable of testing the first assumption in the GF method, because the same assumption is made in the BEC model. The other two

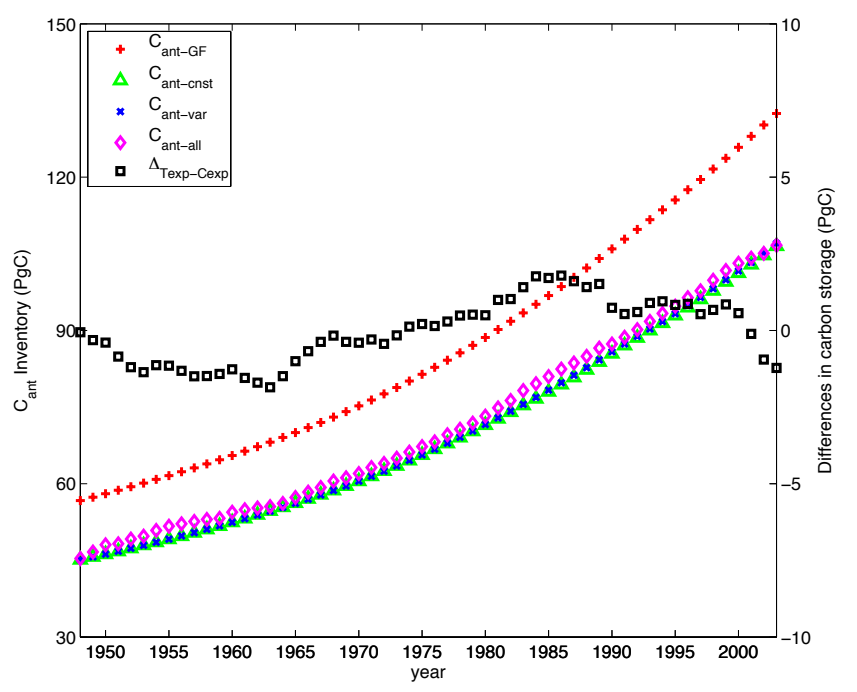

Fig. 4. Changes in the estimated ocean $\mathrm{C}_{\text {ant }}$ inventories, estimated using the GF method and the CCSM, through time (the left axis) and the differences in total DIC inventory from two simulations forced with rising atmospheric $\mathrm{CO}_{2}$ (the right axis). Shown are: $\mathrm{C}_{\text {ant_GF}}\left(\right.$ red crosses); $\mathrm{C}_{\text {ant_cnst }}$ (green triangles); $\mathrm{C}_{\text {ant_var }}$ (blue crosses); $C_{\text {ant_all }}$ (magenta diamonds). The black squares show the differences between total DIC in the Texp and in the Cexp.

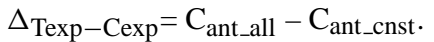


assumptions can, however, be examined with the CCSM simulations. The GF method is not applied to the coupled ocean carbon cycle model in this study as in previous assessments of the $\Delta C^{*}$ method by Matsumoto and Gruber (2005) and of the TTD method by Waugh et al. (2006). Instead, simulation results from different scenarios are analyzed and compared to determine the applicability of the assumptions made in the GF method.

\subsubsection{Assumption of constant circulation}

The second assumption made by the GF method is that ocean circulation is in a cyclo-stationary state, i.e. a seasonally repeating steady state. This assumption is made out of necessity, as there are insufficient observations available to constrain the Green function for a time-varying circulation. The GF method therefore cannot capture the effect of climate change on ocean circulation and hence $\mathrm{CO}_{2}$ uptake. To evaluate the potential errors, we compare changes in global $\mathrm{C}_{\mathrm{ant}}$ inventories estimated using different CCSM simulations and the GF method from 1948 to 2003 (Fig. 4).

As defined in Sect. 2.2, $\mathrm{C}_{\text {ant_cnst }}$ represents the oceanic anthropogenic carbon inventory under constant climate and constant circulation, while $\mathrm{C}_{\text {ant_var }}$ is the net increase in DIC due to rising atmospheric $\mathrm{CO}_{2}$ if changing climate is taken into account. The difference between $\mathrm{C}_{\text {ant_cnst }}$ and $\mathrm{C}_{\text {ant_var }}$ is the difference in $\mathrm{CO}_{2}$ uptake due to changing climate, and thus a measure of the error introduced due to the assumption of constant circulation in the GF method. The globally integrated $\mathrm{C}_{\text {ant_cnst }}$ inventories and $\mathrm{C}_{\text {ant_var }}$ inventories match well in the period from 1948 to 2003 (Fig. 4). The difference between $C_{a n t \_c n s t}$ and $C_{\text {ant_var }}$ is less than $1 \%$ of the $\mathrm{C}_{\mathrm{ant}}$ inventory estimate. To the extent that the variability in the CCSM circulation is representative of the true variability, our comparison implies that possible circulation changes due to climate change during the period of 1948 to 2003 have had little impact on the $\mathrm{C}_{\text {ant }}$ inventory. On a global scale, the assumption of constant circulation for the last few decades that is made in the GF method and the other data-based estimates appears to be a reasonable one.

If the total anthropogenic perturbation on the ocean carbon system is considered, the anthropogenic carbon should be defined as $\mathrm{C}_{\text {ant_all }}$, which includes changes in DIC storage due to both rising atmospheric $\mathrm{CO}_{2}$ and changing climate. The difference between $\mathrm{C}_{\text {ant_all }}$ and $\mathrm{C}_{\text {ant_cnst }}$ is shown as $\Delta_{\text {Texp-Cexp }}$ in Fig. $4 . \Delta_{\text {Texp-Cexp }}$ values vary from $-2 \mathrm{PgC}$ to $2 \mathrm{PgC}$, which are greater than the difference between $\mathrm{C}_{\text {ant_cnst }}$ and $C_{\text {ant_var }}$. Overall difference between $C_{\text {ant_all }}$ and $C_{\text {ant_cnst }}$ are less than $\pm 4 \%$ of the total inventory, which is well within the roughly $20 \%$ uncertainty of the GF method (as well as other data-based techniques). Differences between $\mathrm{C}_{\text {ant_all }}$ and $\mathrm{C}_{\mathrm{ant} \text { _cnst }}$ largely arise from changes in the natural carbon cycle, particularly from the solubility pump. (While the GF method can take into account variations in sea surface temperature, salinity, and winds as it impacts the solubility pump, this was not done in their 2009 study.) The small impact of changing climate on both the natural carbon system and the uptake of $\mathrm{C}_{\mathrm{ant}}$ suggests that the assumption of constant circulation and fixed Green functions are reasonable in the study period for the total anthropogenic perturbation estimate.

Values of $\Delta_{\text {Texp-Cexp }}$ are larger than $4 \mathrm{PgC}$ in the upper $500 \mathrm{~m}$, and account for more than $10 \%$ of the total anthropogenic carbon signal. Vertical profiles of $\mathrm{C}_{\text {ant_all }}$ and $\mathrm{C}_{\text {ant_cnst }}$ also show substantial differences in the upper ocean (Fig. 3). This suggests that the upper-ocean carbon cycle is sensitive to changes in physical fields caused by changing climate, but these differences tend to average out in the integrated carbon inventories. Climate change has had limited impacts on the natural carbon cycle. But it seems likely that both the solubility pump and the biological pump will be increasingly affected in future decades as climate continues to change. A modeling study suggested changes in the natural carbon content may be equivalent to a $5 \%$ reduction in the $\mathrm{C}_{\text {ant }}$ inventory in 1994 (Matsumoto et al., 2010). Thus, the assumption of constant circulation may potentially cause a bias in predictions of the future ocean carbon inventory, although the magnitude of this bias is likely to be smaller than the uncertainty in the GF and other data-based methods for $\mathrm{C}_{\text {ant }}$.

\subsubsection{Assumption about disequilibrium}

The carbon system and $\mathrm{CO}_{2}$ flux are calculated explicitly in the CCSM, as is the air-sea $\mathrm{CO}_{2}$ disequilibrium $\left(\delta p \mathrm{CO}_{2}\right)$. Since ocean uptake of anthropogenic carbon is driven by the change in disequilibrium, it is necessary to have an estimate of the space- and time-varying disequilibrium to accurately estimate $C_{a n t}$ uptake from observations. To address this problem, Khatiwala et al. (2009) assumed that the change in disequilibrium $\left(\delta \Delta p \mathrm{CO}_{2}\right)$ is proportional to the anthropogenic perturbation on the atmospheric $\mathrm{CO}_{2}\left(\delta p \mathrm{CO}_{2}^{\mathrm{atm}}\right)$. This assumption of a linear relationship between $\delta \Delta p \mathrm{CO}_{2}$ and $\delta p \mathrm{CO}_{2}^{\text {atm }}$ was justified on the basis of simulations in an ocean carbon cycle model which showed a similar relationship (Fig. S1 in Khatiwala et al. (2009)). By combining this relationship with surface ocean $p \mathrm{CO}_{2}$ measurements and nonlinear $\mathrm{CO}_{2}$ system chemistry, the GF method can arrive at an estimate of the surface ocean time history of anthropogenic carbon. Here, we assess this assumption with our CCSM simulations, focusing in particular on the effect of climate change. The $\delta \Delta p \mathrm{CO}_{2}$ is calculated using differences of $\delta p \mathrm{CO}_{2}$ between two simulations with reconstructed $\mathrm{CO}_{2}$ concentrations and the pre-industrial $\mathrm{CO}_{2}$ concentration, respectively. Changes in the disequilibrium $\left(\delta \Delta p \mathrm{CO}_{2}\right.$ var $)$ for $\mathrm{C}_{\text {ant }}$ uptake under changing climate are calculated as the difference between $\Delta p \mathrm{CO}_{2}$ in Texp and Fexp. Similarly, in the case including both changes in the natural carbon system and the $\mathrm{C}_{\text {ant }}$ uptake, $\delta \Delta p \mathrm{CO}_{2}$ all is the difference between $\Delta p \mathrm{CO}_{2}$ in Texp and Ctrl. The $\delta p \mathrm{CO}_{2}^{\text {atm }}$ is calculated based 
on the historical atmospheric $\mathrm{CO}_{2}$ records used in the simulations. An approximate linear relationship can be found in simulations under constant climate (Ctrl and Cexp). However, there is a much weaker linear relationship between $\delta \Delta p \mathrm{CO}_{2}$ and $\delta p \mathrm{CO}_{2}^{\mathrm{atm}}$ in the cases that include the effects of changing climate (not shown). There are significant interannual and decadal variations in $\delta \Delta p \mathrm{CO}_{2}$, which do not follow changes in atmospheric $\mathrm{CO}_{2}$ very closely. These variations are mainly due to the effects of varying climate on the natural carbon system and/or the biological pump.

Figure 5 shows the standard errors (SSE) in the linear relationship between $\delta \Delta p \mathrm{CO}_{2 \_ \text {var }}$ and $\delta p \mathrm{CO}_{2}^{\text {atm }}$ and between $\delta \Delta p \mathrm{CO}_{2 \_ \text {all }}$ and $\delta p \mathrm{CO}_{2}^{\text {atm }}$, where $\varepsilon$ in the linear relationship of $\delta \Delta p \mathrm{CO}_{2}=\varepsilon * \delta p \mathrm{CO}_{2}^{\text {atm }}$ is determined using ordinary least squares with data from year 1765 to year 2003. Therefore the errors shown in Fig. 5 are the minimum that could be achieved given the linear relationship assumption. The magnitude of errors in the assumption of linear relationship between $\delta \Delta p \mathrm{CO}_{2 \text { var }}$ and $\delta p \mathrm{CO}_{2}^{\text {atm }}$ are usually $10 \% \sim 25 \%$ of the averaged $\delta \Delta p \mathrm{CO}_{2}$ var. The SSE is generally small in regions where changes in the disequilibrium are small. The errors are larger in the Arctic Ocean, the North Atlantic Ocean, the Equatorial Pacific and the Southern Ocean. The deviations from the assumed linear relationship in the Arctic Ocean are likely due to the presence of sea ice that inhibits the $\mathrm{CO}_{2}$ exchange. The magnitude of SSE in this region is generally $10 \% \sim 30 \%$ of the $\delta \Delta p \mathrm{CO}_{2}$. However, the Arctic Ocean is not included in the GF estimate. There is a significant cancellation of errors when the $\delta \Delta p \mathrm{CO}_{2}$ var is averaged over a 10 -year period, but on shorter time scales substantial errors remain. The SSE is larger than $50 \%$ of the averaged $\delta \Delta p \mathrm{CO}_{2 \_ \text {all }}$ in most of the ocean and more than $100 \%$ in many areas. The errors are also larger in the Arctic Ocean, the North Atlantic Ocean, and increased significantly in the Equatorial Pacific and areas along the Antarctic continental shelf. These errors are mainly due to variations of the natural carbon system under changing climate. The values of SSE are still larger than $2 \mathrm{ppm}$ in many areas after the $\delta \Delta p \mathrm{CO}_{2 \_ \text {all }}$ is smoothed over 10 years. Calculating the history of $\mathrm{CO}_{2}$ flux using the linear relationship may cause significant biases on regional scales, especially in large-SSE regions such as the southernmost Southern Ocean, the North Atlantic Ocean, the Equatorial Pacific Ocean, and areas with high biological productivity. However, it is likely those errors are smoothed out when averaging over large spatial scales (as done in the GF method). It is also possible that positive and negative errors in $\mathrm{C}_{\mathrm{ant}}$ induced by errors in the assumed linear relationship compensate each other when integrated globally, as indicated by the small differences between $\mathrm{C}_{\text {ant_cnst }}, \mathrm{C}_{\text {ant_var }}$ and $\mathrm{C}_{\text {ant_all }}$ (Fig. 4).

Based on analyses of different simulations from 1948 and 2003, the assumptions of constant circulation and linear relationship between $\delta \Delta p \mathrm{CO}_{2}$ and $\delta p \mathrm{CO}_{2}^{\text {atm }}$ in the GF method are acceptable for estimates on the global scale during this period, especially on longer time scales. In the cases, when the complete anthropogenic perturbation is considered, the assumption of constant circulation and linear relationship is likely to cause $\pm 2 \mathrm{PgC}$ uncertainties to the estimate (this can be compared with the roughly $\pm 20 \mathrm{PgC}$ uncertainty in the 2008 estimate of $\mathrm{C}_{\mathrm{ant}}$ based on the GF method). One needs to pay close attention to uncertainties in the assumption. Previous studies suggested that the $\mathrm{CO}_{2}$ flux and the spatial patterns of $p \mathrm{CO}_{2}$ distributions linked closely to variability in the climate forcing (Thomas et al., 2008; Ullman et al., 2009; Le Quéré et al., 2010; Park et al., 2010; Doney et al., 2009; Takahashi et al., 2003; Feely et al., 2006). Some recent research on decadal trends suggested that the efficiency of the ocean to absorb $\mathrm{CO}_{2}$ had decreased in the Southern Ocean and North Atlantic Ocean (Sabine and Gruber, 2006; Corbière et al., 2007; Schuster and Watson, 2007; Metzl, 2009), though others suggested smaller trends in carbon sink based on data on longer timescale and larger spatial scales (McKinley et al., 2011). The uncertainties associated with these assumptions may increase, especially on regional scales, if the ongoing climate change continues to perturb the natural carbon cycle.

\section{Summary}

In this study, three widely used data-based global estimates of oceanic anthropogenic carbon inventories were compared with the $\mathrm{C}_{\mathrm{ant}}$ inventories simulated using BEC/CCSM coupled model under different forcing scenarios. The largest differences among $\mathrm{C}_{\mathrm{ant}}$ estimates occur in the Southern Ocean. Though the integrated $C_{a n t}$ inventories are similar in the North Atlantic Ocean, this is the region of second largest spatial discrepancies between the estimates. The oceanic anthropogenic carbon estimated using different data-based methods show quite different spatial patterns, though the globally integrated $\mathrm{C}_{\text {ant }}$ inventories are consistent. The coupled model can generally reproduce the oceanic anthropogenic carbon inventory and distribution patterns, but it is likely to underestimate the global $C_{a n t}$ inventory. The modeled global inventory of anthropogenic carbon is $92 \mathrm{PgC}$ in simulations with constant climate and the estimates are similar in simulations with changing climate. The model estimates are roughly within the error bars of data-based estimates, but on the low end of the range. The CCSM mainly underestimates the $\mathrm{C}_{\mathrm{ant}}$ inventory in the Southern Ocean and the North Atlantic Ocean. This is primarily due to weak deep mixing and ventilation in those regions in the CCSM. The result is consistent with a previous study by Thornton et al. (2009). The weak Southern Ocean ventilation is partly due to a persistent shallow bias in mixed layer depth. Along the Antarctic Circumpolar Current, mixed layer depths are too shallow by $20-40 \mathrm{~m}$ during summer months, and by more than $100 \mathrm{~m}$ in some regions during winter months. This is thought be a result of missing processes in the model (near inertial wave and Langmuir mixing). Ongoing research is attempting to reduce 

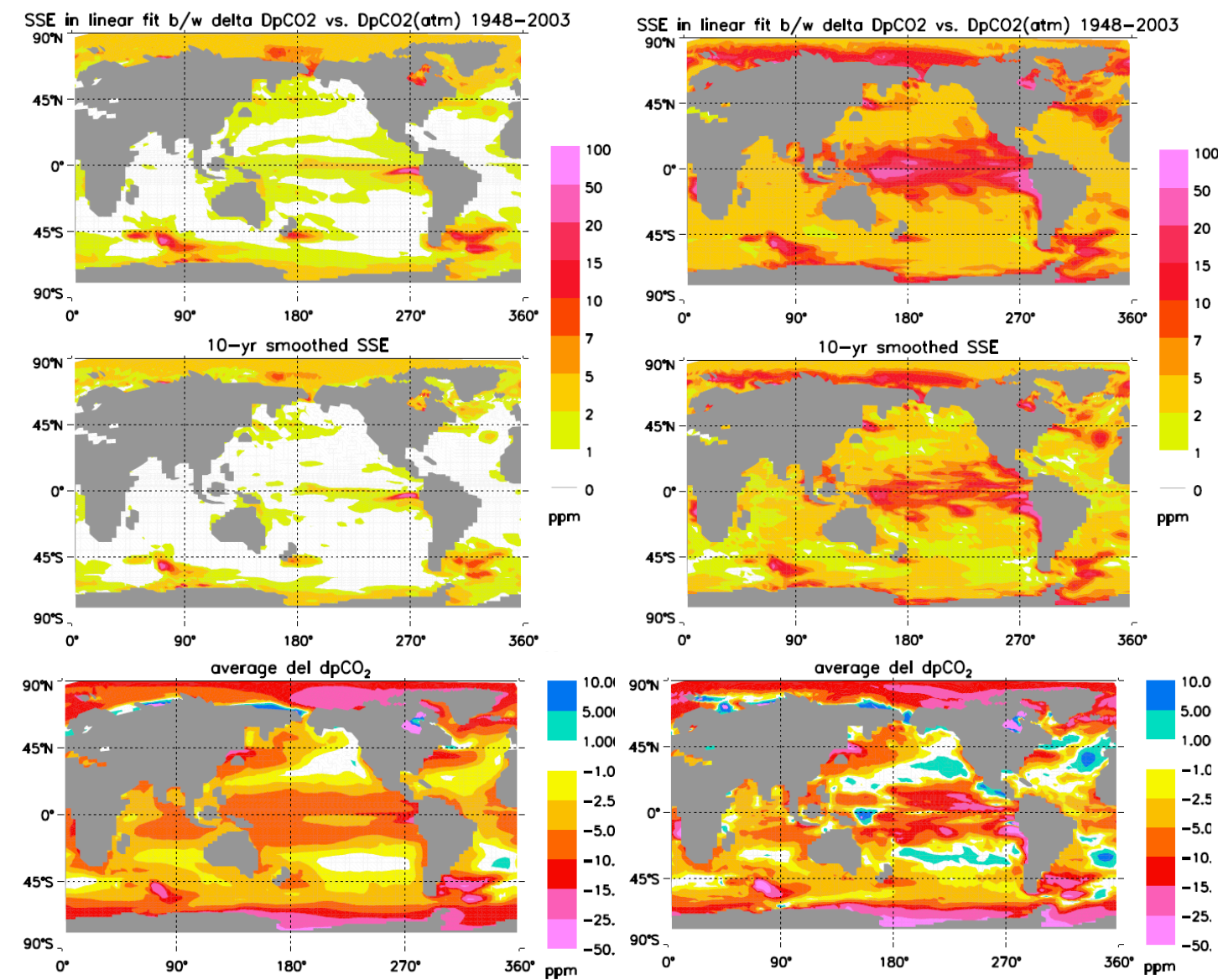

Fig. 5. Maps of the standard error (top two panels) in the linear relationship between $\delta \Delta p \mathrm{CO}_{2}$ and $\delta p \mathrm{CO}_{2}^{\text {atm }}$ with varying climate on annual time scale; maps of $10 \mathrm{yr}$ smoothed standard errors (middle two panels); and maps of mean $\delta \Delta p \mathrm{CO}_{2}$ from 1948-2003 (bottom two panels). Maps on the left column are calculated using the Fexp and the Texp, i.e. $\delta \Delta p \mathrm{CO}_{2}$ var $=\Delta p \mathrm{CO}_{2}(\mathrm{Texp})-\delta p C \mathrm{O}_{2}(\mathrm{Fexp})$. Maps on the right column are calculated using the $\mathrm{Ctrl}$ and the Texp, i.e. $\delta \Delta p \mathrm{CO}_{2 \_ \text {all }}=\Delta p \mathrm{CO}_{2}(\mathrm{Texp})-\Delta p \mathrm{CO}_{2}(\mathrm{Ctrl})$.

this bias and improve ventilation in the Southern Ocean. Further comparisons among different model-based estimates could also help to improve biases in models. Though the $\mathrm{C}_{\text {ant }}$ inventories of $C_{\text {ant_all }}$ and $\mathrm{C}_{\text {ant_cnst }}$ are similar after being integrated, the spatial patterns are different due to impacts of different climate forcing.

The differences between the estimates from the $\Delta C^{*}$ method and the TTD method have been examined in previous studies (Hall et al., 2002; Waugh et al., 2006). Both estimates were significantly biased due to the assumption of constant disequilibrium. The GF method allows the disequilibrium to evolve through time and includes the mixing of waters of different types, and is therefore likely to produce more realistic estimates of $\mathrm{C}_{\mathrm{ant}}$. Overall, the comparisons of vertical and regional distributions of the $\mathrm{C}_{\text {ant }}$ estimates show that the GF method has more advanced skills in estimating the $\mathrm{C}_{\mathrm{ant}}$ inventory and distributions and its estimate of the $\mathrm{C}_{\mathrm{ant}}$ inventory seems reliable for investigating the global $\mathrm{C}_{\text {ant }}$ inventory in the past and for constraining ocean carbon models.
Our simulations suggest that the assumption of constant ocean circulation during the last few decades made by all the data-based estimates is reasonable. There is less than $1 \%$ difference between estimates of the $\mathrm{C}_{\mathrm{ant}}$ inventories under constant climate (constant circulation) and varying climate. If changes in the natural cycle system caused by varying climate are taken into account, the uncertainty due to this assumption is less than $4 \%$ of the $C_{\text {ant }}$ inventory, which falls within the uncertainty of data-based estimates. The accuracy of calculations of the carbon history in the surface ocean is closely related to the linear-relationship assumption. Our analysis suggests that the linear relationship between changes in air-sea disequilibrium and changes in atmospheric $\mathrm{CO}_{2}$ is a good approximation under constant climate. There are substantial errors in the assumption of linear relationship in simulations with changing climate, especially if the complete anthropogenic perturbation on the ocean carbon system is considered. While these errors may cause significant biases in estimates on regional scales and interannual time 
scales, they largely average out on large spatial scales and on time scales of decades or longer. (It is important to note that these errors refer to the surface boundary condition for $\mathrm{C}_{\mathrm{ant}}$, and not the interior concentrations, which depend on the convolution of the boundary condition with the GF.) The GF method depends critically on the assumption that changes in the ocean circulation do not affect the uptake of anthropogenic $\mathrm{CO}_{2}$. Uncertainties in its regional estimates may be larger, especially for the Southern Ocean, North Atlantic and Equatorial Pacific. Recent research on decadal trends shows that the capacity of the ocean to uptake $\mathrm{CO}_{2}$ may have decreased in these regions (Sabine and Gruber, 2006; Corbière et al., 2007; Schuster and Watson, 2007; Metzl, 2009), where the linear relationship assumption may be problematic. The GF method should be used with caution in predicting future oceanic anthropogenic carbon uptake, with careful consideration of uncertainties due to changing climate. These uncertainties are, however, likely to remain smaller than the intrinsic uncertainty of the GF and other data-based methods.

In this study, we have also tried to clarify the definition of anthropogenic carbon in the ocean. For the purpose of closing the carbon budget of the atmosphere, the land and the ocean, the anthropogenic carbon should be defined as the ocean uptake of increased atmospheric $\mathrm{CO}_{2}$ under changing climate. A more broad and complete definition of the anthropogenic perturbation on the ocean carbon system should include the uptake of anthropogenic $\mathrm{CO}_{2}$ and changes in the natural carbon system. Some studies have showed that changes in the natural carbon cycle contributed to observed changes in the DIC, and that transport and distributions of anthropogenic $\mathrm{CO}_{2}$ may be affected by climate variability (Thomas et al., 2008; Wanninkhof et al., 2010). With the knowledge that the global ocean has been undergoing many changes (Hansen et al., 2010; Levitus et al., 2005; Thompson and Solomon, 2002), the broader definition of anthropogenic carbon perturbation should be adopted in global carbon cycle research. So far, model-based assessments have shown that many data-based methods have substantial potential errors (Yool et al., 2010; Waugh et al., 2006; Levine et al., 2008; Matsumoto and Gruber, 2005). It seems that what is needed is reduction and better quantification of errors on regional scales in data-based methods so that model errors can be better pinned down. It is also necessary to further develop the data-based methods and models and to characterize related uncertainties based on sustained observations in order to understand the variability of the ocean carbon system.

Acknowledgements. This work was supported by funding from NASA grants NNG05GR25G and NNX08AB76G to J. K. Moore, and NSF grant OCE 07-27229 to S. Khatiwala. Computations were supported by the Earth System Modeling Facility at University of California, Irvine (NSF ATM-O321380). Thanks to I. Lima and K. Lindsay for support in model simulations used in this study.

Edited by: C. Heinze

\section{References}

Álvarez, M., Lo Monaco, C., Tanhua, T., Yool, A., Oschlies, A., Bullister, J. L., Goyet, C., Metzl, N., Touratier, F., McDonagh, E., and Bryden, H. L.: Estimating the storage of anthropogenic carbon in the subtropical Indian Ocean: a comparison of five different approaches, Biogeosciences, 6, 681-703, doi:10.5194/bg6-681-2009, 2009.

Andreev, A. and Watanabe, S.: Temporal changes in dissolved oxygen of the intermediate water in the subarctic North Pacific, Geophys. Res. Lett., 29, 1680, doi:10.1029/2002gl015021, 2002.

Brewer, P. G.: Direct observation of the oceanic $\mathrm{CO}_{2}$ increase, Geophys. Res. Lett., 5, 997-1000, 1978.

Brown, P. J., Bakker, D. C. E., Schuster, U., and Watson, A. J.: Anthropogenic carbon accumulation in the subtropical North Atlantic, J. Geophys. Res., C, Oceans, 115, C04016, doi:10.1029/2008jc005043, 2010.

Chen, G.-T. and Millero, F. J.: Gradual increase of oceanic $\mathrm{CO}_{2}$, Nature, 277, 205-206, 1979.

Collins, W. D., Bitz, C. M., Blackmon, M. L., Bonan, G. B., Bretherton, C. S., Carton, J. A., Chang, P., Doney, S. C., Hack, J. J., Henderson, T. B., Kiehl, J. T., Large, W. G., McKenna, D. S., Santer, B. D., and Smith, R. D.: The Community Climate System Model Version 3 (CCSM3), J. Climate, 19, 2122-2143, doi:10.1175/JCLI3761.1, 2006.

Conkright, M. E., Locarnini, R. A., Garcia, H. E., O’Brien, T. D., Boyer, T. P., Stephens, C., and Antonov, J. J.: World Ocean Atlas 2001: Objective analysis, data statistics, and figures, CDROM documentation, National Oceanographic Data Center, Silver Spring, MD., 2002.

Corbière, A., Metzl, N., Reverdin, G., Brunet, C., and Takahashi, T.: Interannual and decadal variability of the oceanic carbon sink in the North Atlantic subpolar gyre, Tellus B, 59, 168-178, doi:10.1111/j.1600-0889.2006.00232.x, 2007.

de Boyer Montégut, C., Madec, G., Fischer, A. S., Lazar, A., and Iudicone, D.: Mixed layer depth over the global ocean: An examination of profile data and a profile-based climatology, J. Geophys. Res., 109, C12003, doi:10.1029/2004jc002378, 2004.

Doney, S. C., Lima, I., Feely, R. A., Glover, D. M., Lindsay, K., Mahowald, N., Moore, J. K., and Wanninkhof, R.: Mechanisms governing interannual variability in upper-ocean inorganic carbon system and air-sea $\mathrm{CO}_{2}$ fluxes: Physical climate and atmospheric dust, Deep-Sea Research Part Ii-Topical Studies in Oceanography, 56, 640-655, doi:10.1016/j.dsr2.2008.12.006, 2009.

Feely, R. A., Takahashi, T., Wanninkhof, R., McPhaden, M. J., Cosca, C. E., Sutherland, S. C., and Carr, M.-E.: Decadal variability of the air-sea CO2 fluxes in the equatorial Pacific Ocean, Jo. Geophys. Res., 111, C08S90, doi:10.1029/2005jc003129, 2006.

Friis, K.: A review of marine anthropogenic $\mathrm{CO}_{2}$ definitions: introducing a thermodynamic approach based on observations, Tellus B, 58, 2-15, doi:10.1111/j.1600-0889.2005.00173.x, 2006.

Geider, R. J., MacIntyre, H. L., and Kana, T. M.: A Dynamic Regulatory Model of Phytoplanktonic Acclimation to Light, Nutrients, and Temperature, Limnol. Oceanogr., 43, 679-694, 1998.

Goodkin, N. F., Levine, N. M., Doney, S. C., and Wanninkhof, R.: Impacts of temporal $\mathrm{CO}_{2}$ and climate trends on the detection of ocean anthropogenic $\mathrm{CO}_{2}$ accumulation, Global Biogeochem. Cycles, 25, GB3023, doi:10.1029/2010gb004009, 2011. 
Goyet, C., Coatanoan, C., Eischeid, G., Amaoka, T., Okuda, K., Healy, R., and Tsunogai, S.: Spatial variation of total $\mathrm{CO}_{2}$ and total alkalinity in the northern Indian Ocean: A novel approach for the quantification of anthropogenic $\mathrm{CO}_{2}$ in seawater, J. Mar. Res., 57, 135-163, 1999.

Gruber, N., Sarmiento, J. L., and Stocker, T. F.: An improved method for detecting anthropogenic $\mathrm{CO}_{2}$ in the oceans, Global Biogeochem. Cy., 10, 809-837, doi:10.1029/96gb01608, 1996.

Hall, T. M. and Primeau, F. W.: Separating the natural and anthropogenic air-sea flux of $\mathrm{CO}_{2}$ : The Indian Ocean, Geophys. Res. Lett., 31, L23302, doi:10.1029/2004g1020589, 2004.

Hall, T. M., Haine, T. W. N., and Waugh, D. W.: Inferring the concentration of anthropogenic carbon in the ocean from tracers, Global Biogeochem. Cy., 16, 1131, doi:10.1029/2001gb001835, 2002.

Hall, T. M., Waugh, D. W., Haine, T. W. N., Robbins, P. E., and Khatiwala, S.: Estimates of anthropogenic carbon in the Indian Ocean with allowance for mixing and time-varying airsea $\mathrm{CO}_{2}$ disequilibrium, Global Biogeochem. Cy., 18, GB1031, doi:10.1029/2003gb002120, 2004.

Hansen, J., Sato, M., Ruedy, R., Lo, K., Lea, D. W., and MedinaElizade, M.: Global temperature change, Proceedings of the National Academy of Sciences of the United States of America, 103, 14288-14293, doi:10.1073/pnas.0606291103, 2006.

Hansen, J., Ruedy, R., Sato, M., and Lo, K.: Global surface temperature change, Rev. Geophys., 48, RG4004, doi:10.1029/2010rg000345, 2010.

Houghton, R. A.: Balancing the Global Carbon Budget, Annu. Rev. Earth Pl. Sc., 35, 313-347, doi:10.1146/annurev.earth.35.031306.140057, 2007.

Keeling, R. F.: Comment on "The Ocean Sink for Anthropogenic $\mathrm{CO}_{2}$ ", Science, 308, 1743, doi:10.1126/science.1109620, 2005.

Keller, K., Slater, R. D., Bender, M., and Key, R. M.: Possible biological or physical explanations for decadal scale trends in North Pacific nutrient concentrations and oxygen utilization, Deep-Sea Res. Pt. II, 49, 345-362, doi:10.1016/s0967-0645(01)00106-0, 2002.

Key, R. M., Kozyr, A., Sabine, C. L., Lee, K., Wanninkhof, R., Bullister, J. L., Feely, R. A., Millero, F. J., Mordy, C., and Peng, T. H.: A global ocean carbon climatology: Results from Global Data Analysis Project (GLODAP), Global Biogeochem. Cy., 18, GB4031, doi:10.1029/2004gb002247, 2004.

Khatiwala, S., Primeau, F., and Hall, T.: Reconstruction of the history of anthropogenic $\mathrm{CO}_{2}$ concentrations in the ocean, Nature, 462, 346-349, doi:10.1038/nature08526, 2009.

Large, W. G. and Yeager, S. G.: Diurnal to decadal global forcing for ocean and sea-ice models: the data sets and flux climatologies, NCAR Technical Note NCAR/TN-460+STR., 2004.

Large, W. G. and Yeager, S. G.: The global climatology of an interannually varying air-sea flux data set, Clim. Dynam., 33, 341364, doi:10.1007/s00382-008-0441-3, 2009.

Le Quéré, C., Rodenbeck, C., Buitenhuis, E. T., Conway, T. J., Langenfelds, R., Gomez, A., Labuschagne, C., Ramonet, M., Nakazawa, T., Metzl, N., Gillett, N., and Heimann, M.: Saturation of the Southern Ocean $\mathrm{CO}_{2}$ Sink Due to Recent Climate Change, Science, 316, 1735-1738, doi:10.1126/science.1136188, 2007.
Le Quéré, C., Takahashi, T., Buitenhuis, E. T., Rodenbeck, C., and Sutherland, S. C.: Impact of climate change and variability on the global oceanic sink of CO2, Global Biogeochem. Cy., 24, GB4007, doi:10.1029/2009gb003599, 2010.

Lee, K., Choi, S. D., Park, G. H., Wanninkhof, R., Peng, T. H., Key, R. M., Sabine, C. L., Feely, R. A., Bullister, J. L., Millero, F. J., and Kozyr, A.: An updated anthropogenic $\mathrm{CO}_{2}$ inventory in the Atlantic Ocean, Global Biogeochem. Cy., 17, 1116, doi:10.1029/2003gb002067, 2003.

Levine, N. M., Doney, S. C., Wanninkhof, R., Lindsay, K., and Fung, I. Y.: Impact of ocean carbon system variability on the detection of temporal increases in anthropogenic $\mathrm{CO}_{2}$, J. Geophys. Res., 113, C03019, doi:10.1029/2007jc004153, 2008.

Levitus, S., Antonov, J. I., Boyer, T. P., and Stephens, C.: Warming of the World Ocean, Science, 287, 2225-2229, doi:10.1126/science.287.5461.2225, 2000.

Levitus, S., Antonov, J., and Boyer, T.: Warming of the world ocean, 1955-2003, Geophys. Res. Lett., 32, L02604, doi:10.1029/2004g1021592, 2005.

Lovenduski, N. S., Gruber, N., Doney, S. C., and Lima, I. D.: Enhanced $\mathrm{CO}_{2}$ outgassing in the Southern Ocean from a positive phase of the Southern Annular Mode, Global Biogeochem. Cy., 21, GB2026, doi:10.1029/2006gb002900, 2007.

Luo, C., Mahowald, N. M., and del Corral, J.: Sensitivity study of meteorological parameters on mineral aerosol mobilization, transport, and distribution, J. Geophys. Res., 108, 4447, doi:10.1029/2003jd003483, 2003.

Matear, R. J., Hirst, A. C., and McNeil, B. I.: Changes in dissolved oxygen in the Southern Ocean with climate change, Geochem. Geophys. Geosyst., 1, 1050, doi:10.1029/2000gc000086, 2000.

Matsumoto, K., and Gruber, N.: How accurate is the estimation of anthropogenic carbon in the ocean? An evaluation of the Delta $C^{*}$ method, Global Biogeochem. Cy., 19, GB3014, doi:10.1029/2004gb002397, 2005.

Matsumoto, K., Tokos, K. S., Chikamoto, M. O., and Ridgwell, A.: Characterizing post-industrial changes in the ocean carbon cycle in an Earth system model, Tellus B, 62, 296-313, doi:10.1111/j.1600-0889.2010.00461.x, 2010.

McKinley, G. A., Fay, A. R., Takahashi, T., and Metzl, N.: Convergence of atmospheric and North Atlantic carbon dioxide trends on multidecadal timescales, Nature Geoscience, 4, 606-610, doi:10.1038/ngeo1193, 2011.

Metzl, N.: Decadal increase of oceanic carbon dioxide in Southern Indian Ocean surface waters (1991-2007), Deep-Sea Res. Pt. II, 56, 607-619, doi:10.1016/j.dsr2.2008.12.007, 2009.

Mikaloff Fletcher, S. E., Gruber, N., Jacobson, A. R., Doney, S. C., Dutkiewicz, S., Gerber, M., Follows, M., Joos, F., Lindsay, K., Menemenlis, D., Mouchet, A., Müller, S. A., and Sarmiento, J. L.: Inverse estimates of anthropogenic $\mathrm{CO}_{2}$ uptake, transport, and storage by the ocean, Global Biogeochem. Cy., 20, GB2002, doi:10.1029/2005gb002530, 2006.

Moore, J. K. and Braucher, O.: Sedimentary and mineral dust sources of dissolved iron to the world ocean, Biogeosciences, 5, 631-656, doi:10.5194/bg-5-631-2008, 2008.

Moore, J. K., Doney, S. C., Kleypas, J. A., Glover, D. M., and Fung, I. Y.: An intermediate complexity marine ecosystem model for the global domain, Deep-Sea Res. Pt. II, 49, 403-462, doi:10.1016/S0967-0645(01)00108-4, 2002. 
Moore, J. K., Doney, S. C., and Lindsay, K.: Upper ocean ecosystem dynamics and iron cycling in a global threedimensional model, Global Biogeochem. Cy., 18, GB4028, doi:10.1029/2004gb002220, 2004.

Murata, A., Kumamoto, Y., Sasaki, K., Watanabe, S., and Fukasawa, M.: Decadal increases of anthropogenic $\mathrm{CO}_{2}$ in the subtropical South Atlantic Ocean along 30 degrees S, J. Geophys. Res.-Oceans, 113, C06007, doi:10.1029/2007jc004424, 2008.

Murata, A., Kumamoto, Y., Sasaki, K. I., Watanabe, S., and Fukasawa, M.: Decadal increases of anthropogenic $\mathrm{CO}_{2}$ along 149 degrees $\mathrm{E}$ in the western North Pacific, J. Geophys. Res.-Oceans, 114, C04018, doi:10.1029/2008jc004920, 2009.

Olsen, A., Omar, A. M., Jeansson, E., Anderson, L. G., and Bellerby, R. G. J.: Nordic seas transit time distributions and anthropogenic $\mathrm{CO}_{2}$, J. Geophys. Res., 115, C05005, doi:10.1029/2009jc005488, 2010.

Orr, J. C., Maier-Reimer, E., Mikolajewicz, U., Monfray, P., Sarmiento, J. L., Toggweiler, J. R., Taylor, N. K., Palmer, J., Gruber, N., Sabine, C. L., Le Quéré, C., Key, R. M., and Boutin, J.: Estimates of anthropogenic carbon uptake from four threedimensional global ocean models, Global Biogeochem. Cy., 15, 43-60, doi:10.1029/2000gb001273, 2001.

Palacios, S. L. and Zimmerman, R. C.: Response of eelgrass Zostera marina to $\mathrm{CO} 2$ enrichment: possible impacts of climate change and potential for remediation of coastal habitats, Mar. Ecol.-Prog. Ser., 344, 1-13, doi:10.3354/meps07084, 2007.

Park, G.-H., Wanninkhof, R. I. K., Doney, S. C., Takahashi, T., Lee, K., Feely, R. A., Sabine, C. L., TriÑAnes, J., and Lima, I. D.: Variability of global net sea-air $\mathrm{CO}_{2}$ fluxes over the last three decades using empirical relationships, Tellus B, 62, 352368, doi:10.1111/j.1600-0889.2010.00498.x, 2010.

Peng, T. H. and Wanninkhof, R.: Increase in anthropogenic $\mathrm{CO}_{2}$ in the Atlantic Ocean in the last two decades, Deep-Sea Res. Pt. I, 57, 755-770, doi:10.1016/j.dsr.2010.03.008, 2010.

Peng, T.-H., Wanninkhof, R., Bullister, J. L., Feely, R. A., and Takahashi, T.: Quantification of decadal anthropogenic $\mathrm{CO}_{2}$ uptake in the ocean based on dissolved inorganic carbon measurements, Nature, 396, 560-563, doi:10.1038/25103, 1998.

Peng, T.-H., Wanninkhof, R., and Feely, R. A.: Increase of anthropogenic $\mathrm{CO}_{2}$ in the Pacific Ocean over the last two decades, Deep-Sea Res. Pt. II, 50, 3065-3082, doi:10.1016/j.dsr2.2003.09.001, 2003.

Perez, F. F., Aristegui, J., Vazquez-Rodriguez, M., and Rios, A. F.: Anthropogenic $\mathrm{CO}_{2}$ in the Azores region, Sci. Mar., 74, 11-19, doi:10.3989/scimar.2010.74s1011, 2010a.

Pérez, F. F., Vázquez-Rodrguez, M., Mercier, H., Velo, A., Lherminier, P., and Ríos, A. F.: Trends of anthropogenic $\mathrm{CO}_{2}$ storage in North Atlantic water masses, Biogeosciences, 7, 1789-1807, doi:10.5194/bg-7-1789-2010, 2010b.

Riebesell, U., Schulz, K. G., Bellerby, R. G. J., Botros, M., Fritsche, P., Meyerhofer, M., Neill, C., Nondal, G., Oschlies, A., Wohlers, J., and Zollner, E.: Enhanced biological carbon consumption in a high $\mathrm{CO}_{2}$ ocean, Nature, 450, 545-548, doi:10.1038/nature06267, 2007.

Sabine, C. L. and Gruber, N.: Introduction to special section on North Pacific Carbon Cycle Variability and Climate Change, J. Geophys. Res., 111, C07S01, doi:10.1029/2006jc003532, 2006.
Sabine, C. L., Key, R. M., Johnson, K. M., Millero, F. J., Poisson, A., Sarmiento, J. L., Wallace, D. W. R., and Winn, C. D.: Anthropogenic $\mathrm{CO}_{2}$ inventory of the Indian Ocean, Global Biogeochem. Cy., 13, 179-198, doi:10.1029/1998gb900022, 1999.

Sabine, C. L., Key, R. M., Bullister, J. L., Millero, F. J., Lee, K., Peng, T. H., Tilbrook, B., Ono, T., and Wong, C. S.: Distribution of anthropogenic $\mathrm{CO}_{2}$ in the Pacific Ocean, Global Biogeochem. Cy., 16, 1083, doi:10.1029/2001gb001639, 2002.

Sabine, C. L., Feely, R. A., Gruber, N., Key, R. M., Lee, K., Bullister, J. L., Wanninkhof, R., Wong, C. S., Wallace, D. W. R., Tilbrook, B., Millero, F. J., Peng, T.-H., Kozyr, A., Ono, T., and Rios, A. F.: The Oceanic Sink for Anthropogenic $\mathrm{CO}_{2}$, Science, 305, 367-371, doi:10.1126/science.1097403, 2004.

Sabine, C. L., Key, R. M., Kozyr, A., Feely, R. A., Wanninkhof, R., Millero, F. J., Peng, T.-H., Bullister, J. L., and Lee, K.: Global Ocean Data Analysis Project: Results and Data., ORNL/CDIAC145, NDP-083, Carbon Dioxide Information Analysis Center,Oak Ridge National Laboratory, U.S. Department of Energy, Oak Ridge, Tennessee, 110 pp., 2005.

Sabine, C. L., Feely, R. A., Millero, F. J., Dickson, A. G., Langdon, C., Mecking, S., and Greeley, D.: Decadal changes in Pacific carbon, J. Geophys. Res.-Oceans, 113, C07021, doi:10.1029/2007jc004577, 2008.

Sarmiento, J. L., Orr, J. C., and Siegenthaler, U.: A Perturbation Simulation of $\mathrm{CO}_{2}$ Uptake in an Ocean General Circulation Model, J. Geophys. Res., 97, 3621-3645, doi:10.1029/91jc02849, 1992.

Schuster, U. and Watson, A. J.: A variable and decreasing sink for atmospheric $\mathrm{CO}_{2}$ in the North Atlantic, J. Geophys. Res., 112, C11006, doi:10.1029/2006jc003941, 2007.

Solomon, S., Qin, D., Manning, M., Chen, Z., Marquis, M., Averyt, K. B., Tignor, M., and Miller, H. L.: IPCC Fourth Assessment Report: Climate Change 2007, Cambridge University Press, Cambridge, United Kingdom and New York, NY, USA., 2007.

Stramma, L., Visbeck, M., Brandt, P., Tanhua, T., and Wallace, D.: Deoxygenation in the oxygen minimum zone of the eastern tropical North Atlantic, Geophys. Res. Lett., 36, L20607, doi:10.1029/2009GL039593, 2009.

Takahashi, T., Sutherland, S. C., Feely, R. A., and Cosca, C. E.: Decadal Variation of the Surface Water $p \mathrm{CO}_{2}$ in the Western and Central Equatorial Pacific, Science, 302, 852-856, doi:10.1126/science.1088570, 2003.

Takahashi, T., Sutherland, S. C., Wanninkhof, R., Sweeney, C., Feely, R. A., Chipman, D. W., Hales, B., Friederich, G., Chavez, F., Sabine, C., Watson, A., Bakker, D. C. E., Schuster, U., Metzl, N., Yoshikawa-Inoue, H., Ishii, M., Midorikawa, T., Nojiri, Y., Körtzinger, A., Steinhoff, T., Hoppema, M., Olafsson, J., Arnarson, T. S., Tilbrook, B., Johannessen, T., Olsen, A., Bellerby, R., Wong, C. S., Delille, B., Bates, N. R., and de Baar, H. J. W.: Climatological mean and decadal change in surface ocean $p \mathrm{CO}_{2}$, and net sea-air $\mathrm{CO}_{2}$ flux over the global oceans, Deep-Sea Res. Pt. II, 56, 554-577, doi:10.1016/j.dsr2.2008.12.009, 2009.

Tanhua, T., Kortzinger, A., Friis, K., Waugh, D. W., and Wallace, D. W. R.: An estimate of anthropogenic CO2 inventory from decadal changes in oceanic carbon content, P. Natl. Acad. Sci. USA, 104, 3037-3042, doi:10.1073/pnas.0606574104, 2007. 
Thomas, H., Prowe, A. E. F., Lima, I. D., Doney, S. C., Wanninkhof, R., Greatbatch, R. J., Schuster, U., and Corbiere, A.: Changes in the North Atlantic Oscillation influence $\mathrm{CO}_{2}$ uptake in the North Atlantic over the past 2 decades, Global Biogeochem. Cy., 22, GB4027, doi:10.1029/2007gb003167, 2008.

Thompson, D. W. J. and Solomon, S.: Interpretation of Recent Southern Hemisphere Climate Change, Science, 296, 895-899, doi:10.1126/science.1069270, 2002.

Thornton, P. E., Doney, S. C., Lindsay, K., Moore, J. K., Mahowald, N., Randerson, J. T., Fung, I., Lamarque, J.-F., Feddema, J. J., and Lee, Y.-H.: Carbon-nitrogen interactions regulate climate-carbon cycle feedbacks: results from an atmosphereocean general circulation model, Biogeosciences, 6, 2099-2120, doi:10.5194/bg-6-2099-2009, 2009.

Tjiputra, J. F., Assmann, K., and Heinze, C.: Anthropogenic carbon dynamics in the changing ocean, Ocean Sci., 6, 605-614, doi:10.5194/os-6-605-2010, 2010.

Touratier, F. and Goyet, C.: Definition, properties, and Atlantic Ocean distribution of the new tracer TrOCA, J. Mar. Sys., 46, 169-179, doi:10.1016/j.jmarsys.2003.11.016, 2004.

Touratier, F., Azouzi, L., and Goyet, C.: CFC-11, $\Delta 14 \mathrm{C}$ and $3 \mathrm{H}$ tracers as a means to assess anthropogenic $\mathrm{CO}_{2}$ concentrations in the ocean, Tellus B, 59, 318-325, doi:10.1111/j.16000889.2006.00247.x, 2007.

Ullman, D. J., McKinley, G. A., Bennington, V., and Dutkiewicz, S.: Trends in the North Atlantic carbon sink: 1992-2006, Global Biogeochem. Cy., 23, GB4011, doi:10.1029/2008gb003383, 2009.

Vázquez-Rodríguez, M., Touratier, F., Lo Monaco, C., Waugh, D. W., Padin, X. A., Bellerby, R. G. J., Goyet, C., Metzl, N., Ríos, A. F., and Pérez, F. F.: Anthropogenic carbon distributions in the Atlantic Ocean: data-based estimates from the Arctic to the Antarctic, Biogeosciences, 6, 439-451, doi:10.5194/bg-6-4392009, 2009.
Wang, S. and Moore, J. K.: Incorporating Phaeocystis into a Southern Ocean ecosystem model, J. Geophys. Res., 116, C01019, doi:10.1029/2009jc005817, 2011.

Wang, S. and Moore, J. K.: Variability of primary production and air-sea $\mathrm{CO}_{2}$ flux in the Southern Ocean, Global Biogeochem. Cy., 26, GB1008, doi:10.1029/2010GB003981, 2012.

Wanninkhof, R., Doney, S. C., Bullister, J. L., Levine, N. M., Warner, M., and Gruber, N.: Detecting anthropogenic $\mathrm{CO}_{2}$ changes in the interior Atlantic Ocean between 1989 and 2005, J. Geophys. Res.-Oceans, 115, C11028, doi:10.1029/2010jc006251, 2010.

Waugh, D. W., Haine, T. W. N., and Hall, T. M.: Transport times and anthropogenic carbon in the subpolar North Atlantic Ocean, Deep-Sea Res. Pt. I, 51, 1475-1491, doi:10.1016/j.dsr.2004.06.011, 2004

Waugh, D. W., Hall, T. M., McNeil, B. I., Key, R., and Matear, R. J.: Anthropogenic $\mathrm{CO}_{2}$ in the oceans estimated using transit time distributions, Tellus B, 58, 376-389, doi:10.1111/j.16000889.2006.00222.x, 2006.

Wetzel, P., Winguth, A., and Maier-Reimer, E.: Sea-to-air $\mathrm{CO}_{2}$ flux from 1948 to 2003: A model study, Global Biogeochem. Cy., 19, GB2005, doi:10.1029/2004gb002339, 2005.

$\mathrm{Xu}$, Y. and $\mathrm{Li}, \mathrm{Y}$ : : Estimates of anthropogenic $\mathrm{CO}_{2}$ uptake in a global ocean model, Adv. Atmos. Sci., 26, 265-274, doi:10.1007/s00376-009-0265-z, 2009.

Yeager, S. G., Shields, C. A., Large, W. G., and Hack, J. J.: The Low-Resolution CCSM3, J. Climate, 19, 2545-2566, doi:10.1175/JCLI3744.1, 2006.

Yool, A., Oschlies, A., Nurser, A. J. G., and Gruber, N.: A modelbased assessment of the TrOCA approach for estimating anthropogenic carbon in the ocean, Biogeosciences, 7, 723-751, doi:10.5194/bg-7-723-2010, 2010. 